\title{
IPCC global coupled model simulations of the South America monsoon system
}

\author{
Rodrigo J. Bombardi · Leila M. V. Carvalho
}

Received: 16 May 2008/ Accepted: 24 October 2008/Published online: 15 November 2008

(C) Springer-Verlag 2008

\begin{abstract}
This study examines the variability of the South America monsoon system (SAMS) over tropical South America (SA). The onset, end, and total rainfall during the summer monsoon are investigated using precipitation pentad estimates from the global precipitation climatology project (GPCP) 1979-2006. Likewise, the variability of SAMS characteristics is examined in ten Intergovernmental Panel on Climate Change (IPCC) global coupled climate models in the twentieth century (1981-2000) and in a future scenario of global change (A1B) (2081-2100). It is shown that most IPCC models misrepresent the intertropical convergence zone and therefore do not capture the actual annual cycle of precipitation over the Amazon and northwest SA. Most models can correctly represent the spatiotemporal variability of the annual cycle of precipitation in central and eastern Brazil such as the correct phase of dry and wet seasons, onset dates, duration of rainy season and total accumulated precipitation during the summer monsoon for the twentieth century runs. Nevertheless, poor representation of the total monsoonal precipitation over the Amazon and northeast Brazil is observed in a large majority of the models. Overall, MIROC3.2-hires, MIROC3.2-medres and MRI-CGCM3.2.3 show the most realistic representation of SAMS's characteristics such as onset, duration, total monsoonal precipitation, and its interannual variability. On the other hand, ECHAM5, GFDL-CM2.0 and GFDL-CM2.1 have
\end{abstract}

R. J. Bombardi $(\bowtie) \cdot$ L. M. V. Carvalho

Department of Atmospheric Sciences, University of Sao Paulo,

Rua do Matão, 1226, Sao Paulo, SP 05508-090, Brazil

e-mail: bombardi@model.iag.usp.br

L. M. V. Carvalho

Institute for Computational Earth System Science, University

of California Santa Barbara, Santa Barbara, USA the least realistic representation of the same characteristics. For the A1B scenario the most coherent feature observed in the IPCC models is a reduction in precipitation over central-eastern Brazil during the summer monsoon, comparatively with the present climate. The IPCC models do not indicate statistically significant changes in SAMS onset and demise dates for the same scenario.

Keywords South America monsoon system . Climate change $\cdot$ Global change .

IPCC global coupled climate models · A1B scenario

\section{Introduction}

Tropical South America (SA) is under the influence of a monsoon regime. Unlike other monsoon systems, easterly winds dominate during the entire year over northern SA and tropical Atlantic. Zhou and Lau (1998) demonstrated that when the annual mean is removed from winter and summer composites, a clear reverse in the low-level circulation monthly anomalies becomes evident, which supports the existence of the South America monsoon system (SAMS). The beginning of the summer monsoon in SA is characterized by the increase in convective activity over northwest Amazon that progressively intensifies over southeast SA (Kousky 1988; Marengo et al. 2001; Liebmann and Marengo 2001; Gan et al. 2004; Vera et al. 2006a). Over central and southeast Brazil the onset of the rainy season is observed between September and November whereas the demise of the rainy season is observed between March and April (Gan et al. 2004; Silva and Carvalho 2007).

Another prominent feature during the rainy season in tropical SA is the presence of a northwest-southeast 
oriented band of clouds and precipitation that originates in the Amazon and runs toward the subtropical Atlantic, which is known as the South Atlantic convergence zone (SACZ) (Kodama 1992). The SACZ is, therefore, an important component of SAMS and plays a significant role in the rainfall variability during the rainy season over central and southeast Brazil (Liebmann et al. 2001; Carvalho et al. 2002a, 2004). Moreover, the monsoon regime in SA is characterized by large spatial (Carvalho et al. 2002a, 2004) and temporal variability from intraseasonal to interannual timescales (Kayano and Kousky 1992; Lenters and Cook 1999; Grimm et al. 1998; Jones and Carvalho 2002; Carvalho et al. 2002b; Vera et al. 2006a; Silva and Carvalho 2007).

The Earth's average surface temperature has increased by $0.6 \pm 0.2^{\circ} \mathrm{C}$ since the late nineteenth century with global impacts. The response of the climate system to the rapid increase of greenhouse gases remains uncertain Intergovernmental Panel on Climate Change (IPCC 2007). Nevertheless, recent studies have indicated that climate changes resulting from the increase of $\mathrm{CO}_{2}$ may affect the intensity and frequency of extremes temperature and precipitation in several regions over the globe with large socio-economical implications (Kharin et al. 2007). Over SA, modifications in the probability of extremes will have significant impacts on water resources, endangered ecosystems, agriculture, and human health (IPCC 2001). In recent years, the implications of global warming to the spatiotemporal variability of precipitation in monsoon regimes have received further attention. Ashrit et al. (2003), for instance, examined transient climate change simulations of the CNRM ocean-atmosphere coupled climate model (CCM) with increase in greenhouse gases. Their focus was on the Indian summer monsoon and El Niño southern oscillation (ENSO) teleconnections. They found no clear strengthening of the monsoon circulation but an increase in the monsoon precipitation likely linked to large increase in precipitable water over India due to global warming.

Labraga and Lopez (1997) and Carril et al. (1997) are some of the earliest studies that have investigated the impacts on SA precipitation in a future scenario with double the present $\mathrm{CO}_{2}$ concentration. Labraga and Lopez (1997) examined simulations of five general circulation models coupled to an oceanic model with a single mixing layer, whereas Carril et al. (1997) evaluated four simulations of early versions of the IPCC coupled models. Both studies indicate an increase in precipitation over west Pacific inter-tropical convergence zone (ITCZ) and west coast of $\mathrm{SA}$ as a response to the increase in $\mathrm{CO}_{2}$. Giorgi and Francisco (2000) examined models from the third assessment report (IPCC 2001), which are an earlier generation of models. They evaluated five IPCC coupled models in four distinct future scenarios and verified an increase of about $10 \%$ in precipitation over tropical SA during December-February season. According to Meehl et al. (2005), a warmer climate implies a larger availability of water vapor in the atmosphere and a larger capacity of the air to retain humidity. With more humidity in the atmosphere, relatively more intense rainfall and/or potentially strong snowstorms can occur.

Although most IPCC models have improved since the third assessment report (IPCC 2001), there are still many uncertainties and discrepancies among models in some regions. For instance, a large majority of the IPCC models underestimate precipitation over tropical SA including the Amazon (Sun et al. 2005; Dai 2006; Vera et al. 2006b). On the other hand, Vera et al. (2006b) investigated seasonal precipitation over SA using seven global coupled IPCC models and observed that most models reproduce the mean basic characteristics of the annual cycle of precipitation, such as the seasonal migration of convection over tropical SA and the maximum precipitation observed over southern Andes. Nevertheless, models diverge in the location and intensity of that maximum. Other remarkable discrepancies discussed in Vera et al. (2006b) are associated with the SACZ. Some models (GFDL, MIROC ad MRI) represent the SACZ intensity and location similar to observations, whereas for a few others the SACZ is displaced northeastward of its climatological position or is even absent.

Most previous studies discussed here have focused mainly on the skill of the global climate models in representing the mean seasonal intensity, frequency and largescale patterns of precipitation in the present climate and future scenarios of global change due to increase in greenhouse gases. However, some characteristics of the monsoon regime such as the onset and duration of the rainy season and total precipitation, which are essential for water resource management and agriculture, have not been properly examined yet. Large variations in these characteristics due to global warming will imply in a significant socio-economic impacts for all SA counties. In the present study we examine the ability of ten IPCC global coupled models in realistically simulating SAMS onset and demise dates, as well as the total summer monsoon precipitation in the present climate (1981-2000). Likewise, we investigate future projections of these models for the A1B scenario with twice the present $\mathrm{CO}_{2}$ concentration (2081-2100). The identification of the performance of individual IPCC models in simulating SAMS characteristics will be useful to detect regions of large and poor reliability for the interpretation of projections in future scenarios of climate change.

This study is organized as follows: data and models are presented in Sect. 2. Section 3 discusses the method applied to define the monsoon onset, demise and total 
precipitation. Sections 4-7 discuss the IPCC simulations of the monsoon characteristics for the present climate. Section 8 shows the IPCC projections for the A1B scenario. The main conclusions are presented in Sect. 9.

\section{Data}

Precipitation data used in this study are 5-day mean (pentad) rainfall from the global precipitation climatology project (GPCP) from 1979 to 2006 . The GPCP pentad is based on station gauges and satellite estimates with spatial resolution $2.5^{\circ} \times 2.5^{\circ}$ lat/lon (Xie et al. 2003). The advantage of using GPCP is its global coverage, including oceanic areas. In addition, Muza and Carvalho (2006) have shown that GPCP shows a good correspondence with gridded precipitation from stations (Liebmann and Allured 2005) in areas over tropical and subtropical Brazil. The domain examined in the present study extends from $5.0^{\circ} \mathrm{N}-$ $35.0^{\circ} \mathrm{S}$ to $30.0^{\circ} \mathrm{W}-80^{\circ} \mathrm{W}$.

South America monsoon system characteristics are examined in ten IPCC CCMs (Table 1) in the same domain and in two distinct periods: the present climate (i.e. 19792000) and for the A1B scenario (2080-2100). Data were obtained from the archives of the world climate research programme's (WCRP's) coupled model intercomparison project phase 3 (CMIP3) multi-model data set. In the A1B scenario the maximum greenhouse gases emission is reached in the middle of the twenty-first century and corresponds to approximately a double of the present concentration (i.e. 700 ppmv). Concentrations of $\mathrm{CH}_{2}$ and $\mathrm{N}_{2} \mathrm{O}$ in the same period are about 2.0 and $0.37 \mathrm{ppmv}$, respectively (e.g. Kharin et al. 2007).

All IPCC models discussed here are coupled models with precipitation on daily resolution and with integrations available in the two distinct periods indicated above. In addition, all models have at least $2.8^{\circ}$ spatial resolution. In order to compare observations and simulations in the present climate, pentad precipitation was calculated for all models. There is more than one simulation available for FGOALSg1.0, MIROC3.2-medres, and MRI-CGCM2.3.2 models in both scenarios (Table 1). Therefore, all simulations available for these three models are considered in this work.

All IPCC models examined here have atmospheric and oceanic components. However, no model has dynamical vegetation. Only CNRM-CM3 has ozone transport and simplified atmospheric chemistry reactions (Cariolle and Déqué 1986; Cariolle et al. 1990). With the exception of GFDL-CM2.0 and GFDL-CM2.1 that do not include aerosols, all other models include some type of aerosol, in general sulfates. MIROC3.2-hires and MIROC3.2-medres, and MPI-ECHAM5 include indirect effects of the aerosols. CGCM3.1(T63) and MRI-CGCM2.3.2 have global flux adjustment for heat and water and the MRI-CGCM2.3.2 has momentum adjustment between $12^{\circ} \mathrm{N}$ and $12^{\circ} \mathrm{S}$. The only difference between MIROC3.2-hires and MIROC3.2medres is the resolution, whereas GFDL-CM2.0 and GFDL-CM2.1 differ in the numeric scheme for atmospheric advection (Dai 2006).

\section{Method to estimate SAMS onset, end and total precipitation}

The onset, end and duration of SAMS are determined based on the method adapted from Liebmann and Marengo (2001). For every grid point, the following summation is computed:

$S($ pentad $)=\sum_{n=\text { pentad } 0}^{\text {pentad }}(R(n)-\bar{R})$

where $R(n)$ is the mean precipitation for the pentad $n$ (mm/day), and $\bar{R}$ is the climatological annual mean daily precipitation $\left(\mathrm{mm} /\right.$ day). The initial pentad $\left(\operatorname{pentad}_{0}\right)$ is

Table 1 Model description: name, country, spatial resolution, number of simulations for both scenarios twentieth century (20CM) and A1B, and key reference for each model

\begin{tabular}{|c|c|c|c|c|c|}
\hline Model name & Center country & Resolution lat $\times$ lon & $20 \mathrm{CM}$ runs & A1B runs & Key reference \\
\hline CGCM3.1(T63) & Canada & $\sim 2.8 \times 2.8$ & 1 & 1 & Flato et al. (2000) \\
\hline CSIRO-Mk3.0 & Australia & $\sim 1.9 \times 1.9$ & 1 & 1 & Gordon et al. (2002) \\
\hline CNRM-CM3 & France & $\sim 2.8 \times 2.8$ & 1 & 1 & Salas-Mélia et al. (2005) \\
\hline ECHAM5 & Germany & $\sim 1.9 \times 1.9$ & 1 & 1 & Roeckner et al. (2003) \\
\hline FGOALS-g1.0 & China & $\sim 2.8 \times 2.8$ & 3 & 3 & Yu et al. (2004) \\
\hline GFDL-CM2.0 & USA & $2.0 \times 2.5$ & 1 & 1 & Delworth et al. (2006) \\
\hline GFDL-CM2.1 & USA & $2.0 \times 2.5$ & 1 & 1 & Delworth et al. (2006) \\
\hline MIROC3.2-hires & Japan & $\sim 1.125 \times 1.125$ & 1 & 1 & Hasumi and Emori (2004) \\
\hline MIROC3.2-medres & Japan & $\sim 2.8 \times 2.8$ & 2 & 2 & Hasumi and Emori (2004) \\
\hline MRI-CGCM2.3.2 & Japan & $\sim 2.8 \times 2.8$ & 5 & 5 & Yukimoto et al. (2006) \\
\hline
\end{tabular}


always taken within the dry season such that the onset is never missed (Liebmann and Marengo 2001). In the present study the initial pentad is computed for every grid point as the pentad in which the minimum climatological daily rainfall is observed. Figure 1 shows an example of the application of Eq. 1 to estimate the onset and end of the rainy season. During the dry season $S$ (Eq. 1) shows negative slope. As the wet season starts rainfall becomes more regular and, consequently, the $S$ slope becomes steadily positive. When daily precipitation decreases and/or becomes less regular the $S$ slope becomes steadily negative again, which indicates that the dry season has begun. In order to accurately estimate the onset and demise of SAMS, $S$ is further smoothed $(\bar{S})$ by applying a moving average filter and the first derivative $\mathrm{d} \bar{S} / \mathrm{d} t$ is then computed (Fig. 1). SAMS onset (demise) is assumed to be the pentad when $\mathrm{d} \bar{S} / \mathrm{d} t=0$, followed by the pentad when $\mathrm{d} \bar{S} / \mathrm{d} t>0(\mathrm{~d} \bar{S} / \mathrm{d} t<0)$. The total precipitation during the summer monsoon is the total precipitation that is accumulated from the onset to the demise dates.

\section{Summer daily precipitation}

We start our discussion about the performance of the IPCC models in simulating the characteristics of SAMS in the present climate (hereafter referred to as $20 \mathrm{CM}$ ) by showing

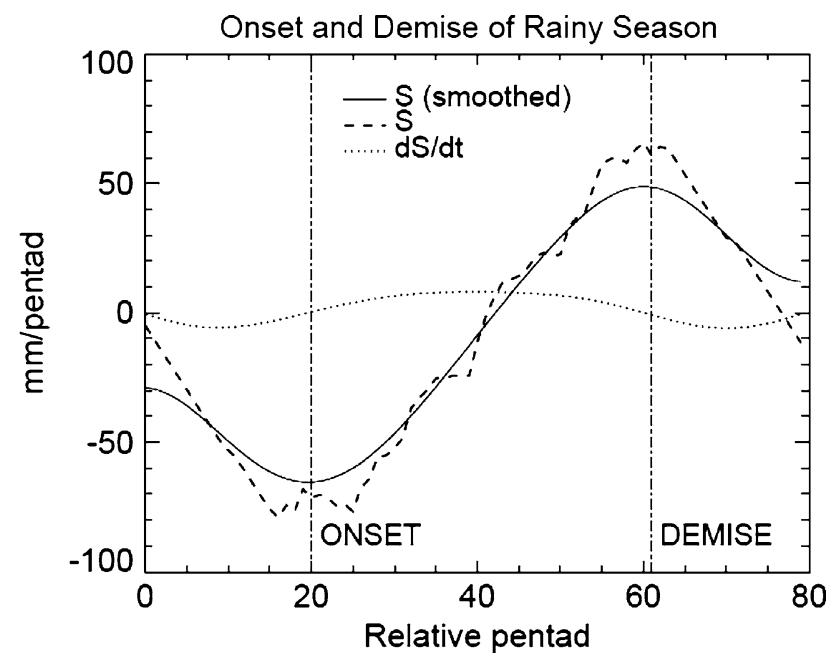

Fig. 1 Example of application of the method adapted from Liebmann and Marengo (2001) to determine the onset and demise of the rainy season. Dashed line represents the $S$ estimate (Eq. 1); continuous line indicates the smoothed $S$ estimate (three point moving average passed over 40 times); doted line indicates the first derivative of the smoothed $S$ estimate. Curves are shown as a function of time starting from the initial pentad $\left(\right.$ pentad $\left._{0}\right)$ and the ordinate represents the accumulated precipitation anomaly $(\mathrm{mm} /$ pentad). Changes in the slope of $S(\mathrm{~d} S / \mathrm{d} t)$ define the onset $(\mathrm{d} S / \mathrm{d} t>0)$ and demise $(\mathrm{d} S / \mathrm{d} t<0)$ of the rainy season the observed and simulated daily mean and standard deviation rainfall $(\mathrm{mm} / \mathrm{day})$ during the peak of the rainy season (December-February, DJF) (Fig. 2). We recall that all simulations available for FGOALS-g1.0, MIROC3.2medres, and MRI-CGCM2.3.2models (Table 1) are considered in the analysis. The GPCP (Fig. 2a) indicates the presence of a NW-SE oriented band with daily precipitation above $3 \mathrm{~mm} /$ day extending from the Amazon toward subtropical Atlantic, which has been characterized as the SACZ (e.g. Carvalho et al. 2002a). Over the continent, the maximum precipitation ( $\sim 9 \mathrm{~mm} /$ day $)$ is observed over central Amazon, consistent with Carvalho et al. (2004). Another region with maximum daily precipitation is observed in association with the Atlantic ITCZ. In addition, the SACZ and the ITCZ (Fig. 2a) are both related to large precipitation variance as the result of the interplay of phenomena occurring in a broad range of timescales (e.g. Grimm et al. 2000; Carvalho et al. 2002b; Silva et al. 2006).

The IPCC models (Fig. 2b-k), in general, capture the main spatial patterns of the summer (DJF) mean daily precipitation, such as the precipitation maxima over the continent and in association with the ITCZ and SACZ. Nevertheless, most IPCC models simulate the continental maximum displaced southeastward of its actual position, approximately co-located with the Brazilian highland. These results are consistent with the patterns of seasonal mean precipitation shown in Lambert and Boer (2001) and Vera et al. (2006b). The displacement is particularly noticeable for ECHAM5 (Fig. 2e) that misplaces the maximum precipitation toward west tropical Atlantic, as an extension of the Atlantic ITCZ. In addition, ECHAM5 (Fig. 2e) does not reproduce an NW-SE oriented band of precipitation observed in all other IPCC models examined here. These characteristics are particular of this version of the model in contrast with previous versions (e.g. ECHAM4.5) that show a much more realistic representation of SAMS (Liebmann et al. 2007). Another issue in the representation of the seasonal precipitation in the IPCC models is the unrealistic double ITCZ pattern observed for GFDL-CM2.0 (Fig. 2g), GFDL-CM2.a (Fig. 2h) and MIROC3.2-hires (Fig. 2i) (Dai 2006). MIROC3.2-medres (Fig. 2j) and MRI-CGCM2.3.2 (Fig. 2k) (both with $2.8^{\circ}$ resolution) show an unrealistic wide ITCZ. The other feature simulated in all models (Fig. 2b-k) that is not observed in GPCP (Fig. 2a) is the maximum precipitation along the Andes.

Nevertheless, the IPCC models that realistically simulate the mean daily DJF precipitation over the convergence zones simulate fairly well the observed precipitation variability, represented here by the standard deviation of daily DJF precipitation and indicated by shades in Fig. 2. Overall, MIROC3.2-hires (Fig. 2i) has the best representation of the SACZ in regard to its mean summer daily 
Fig. 2 Daily mean precipitation (contours) during the peak of the rainy season (DecemberFebruary) and standard deviation ( $\mathrm{mm} /$ day) (shading). Contour interval is equal $3 \mathrm{~mm} /$ day. Dark gray indicates standard deviation above $5 \mathrm{~mm} /$ day and light gray shows standard deviation between 3 and $5 \mathrm{~mm} /$ day. Regions with $n o$ shading indicate standard deviation below $3 \mathrm{~mm} /$ day. a GPCP; b CGCM3.1(T63); c CNRM-CM3; d CSIRO-Mk3.0; e ECHAM5; f FGOALS-g1.0; g GFDL-CM2.0; h GFDLCM2.1; i MIROC3.2-hires; j MIROC3.2-medres; k MRI-CGCM2.3.2 (a) GPCP

(b) CGCMT63 (20CM)
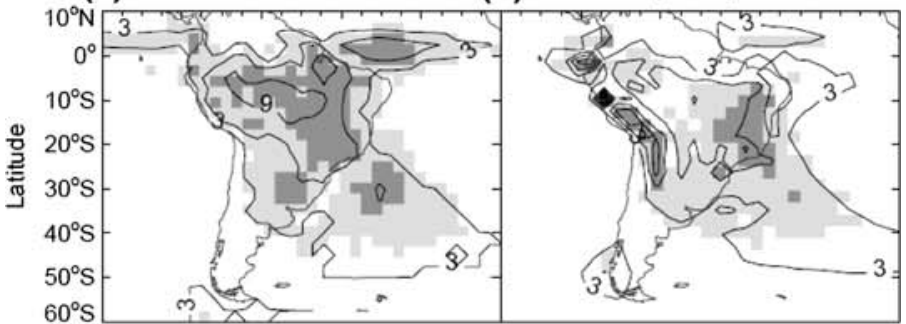

(c) CNRM (20CM)

(d) CSIRO (20cM)

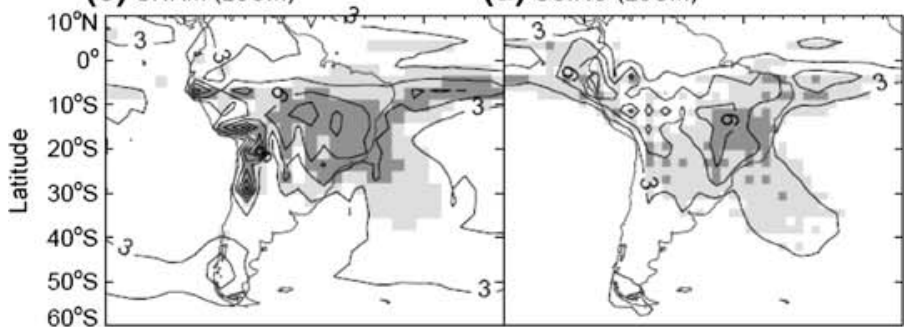

(e) ECHAM5 (20CM)

(f) FGOALS (20CM)

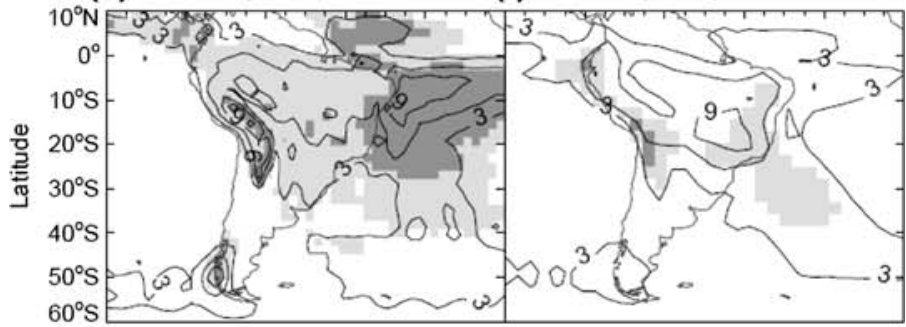

(g) GFDL2.0 (20CM)

(h) GFDL2.1 (20CM)

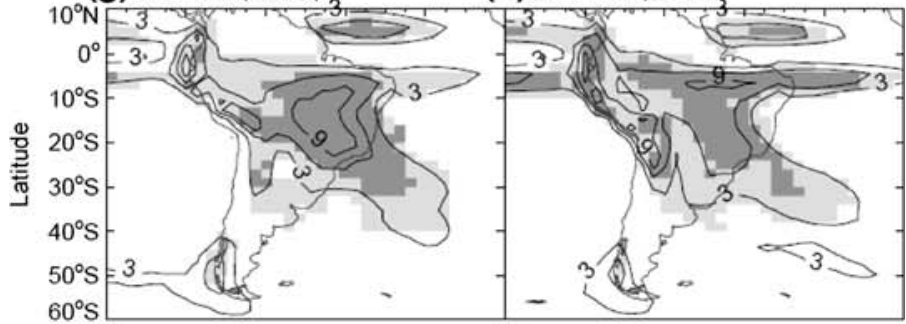

(i) MIROC-H (20CM)

(j) MIROC-M (20CM)

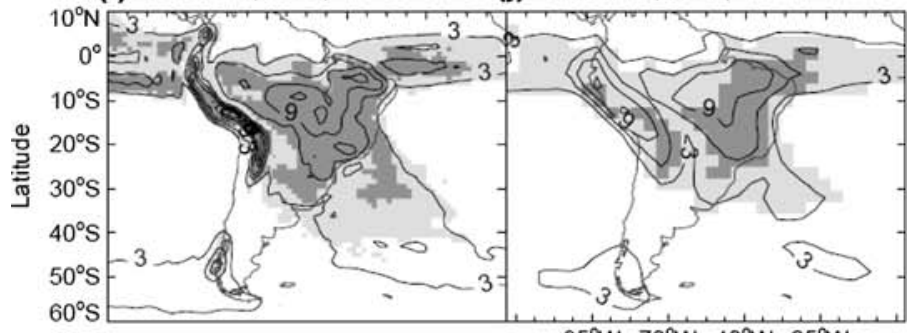

(k) MRI $(20 \mathrm{CM})$

$85^{\circ} \mathrm{W} 70^{\circ} \mathrm{W} 40^{\circ} \mathrm{W} 25^{\circ} \mathrm{W}$ Longitude




precipitation and standard deviation features. For instance, MIROC3.2-hires is the only model among the ten models that simulates mean daily DJF precipitation between 6 and $9 \mathrm{~mm} /$ day over southeast Brazil, with standard deviation comparable to observations. Moreover, the maximum daily precipitation in MIROC3.2-hires ( $\sim 9 \mathrm{~mm} /$ day) is displaced toward central Amazon in agreement with GPCP. These features are reasonably well represented in GFDLCM2.0 (Fig. 2g), GFDL-CM2.1 (Fig. 2h), and MIROC3.2medres (Fig. 2j). FGOALS-g1.0 (Fig. 3f) and ECHAM5
(Fig. 3e) on the other hand, show a very poor representation of the SACZ and ITCZ with respect to both mean precipitation and standard variation.

\section{Precipitation annual cycle}

Realistic simulations of SAMS characteristics depend on the ability of models to reproduce the observed precipitation annual cycle. Figure 3 shows the climatological annual
Fig. 3 Observed and simulated annual cycle of precipitation for the 20CM run. The mean annual cycle is obtained in an area corresponding to $5^{\circ}$ latitude/ longitude for the regions a northwestern SA, b western Amazon, c Amazon mouth, d southern Amazon, e central Amazon, $\mathbf{f}$ central Brazil and g SACZ over South Atlantic (a) Selected Regions

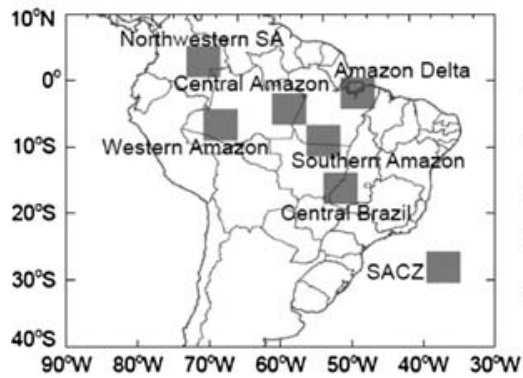

(c) Amazon Mouth $(0.0 \times 50 \mathrm{~W})$

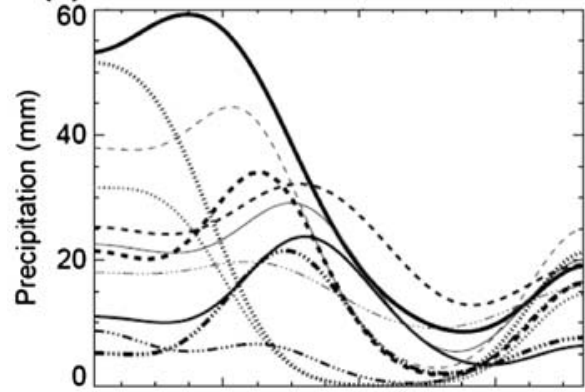

(e) Central Amazon (5S $\times 60 \mathrm{~W}$ )

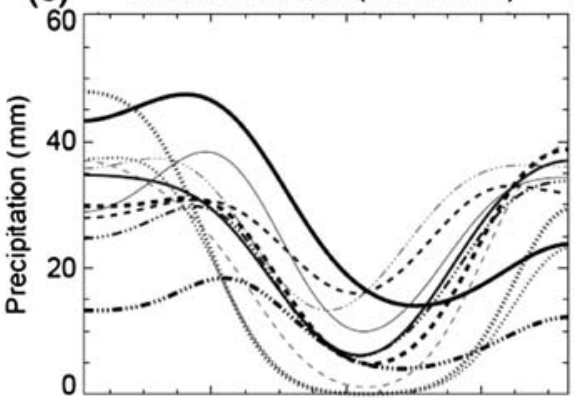

(g) Central Brazil (17.5S $\times 50 \mathrm{~W})$

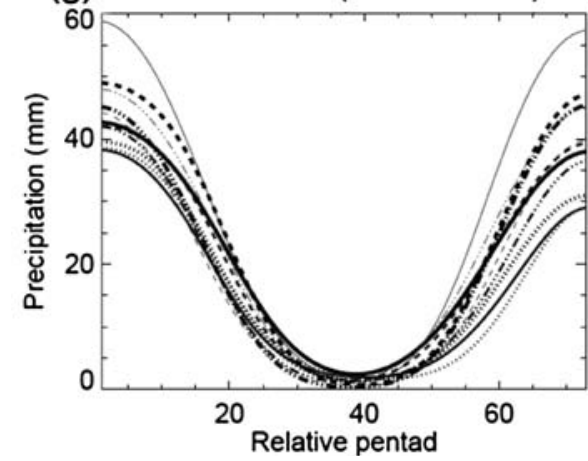

(b) NW AS $(2.5 \mathrm{~N} \times 72.5 \mathrm{~W})$

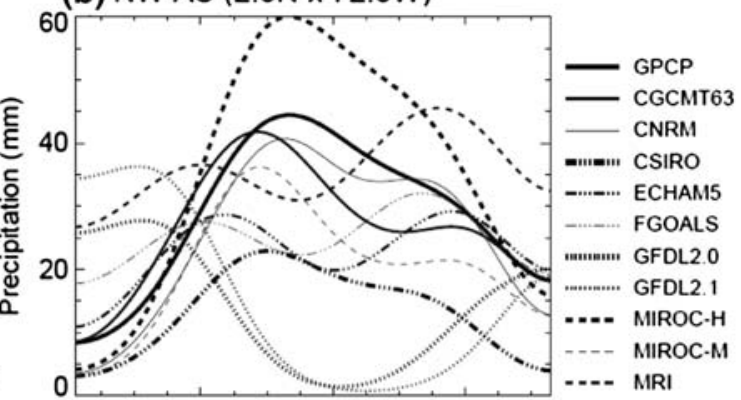

(d) Western Amazon (5S x 70W)

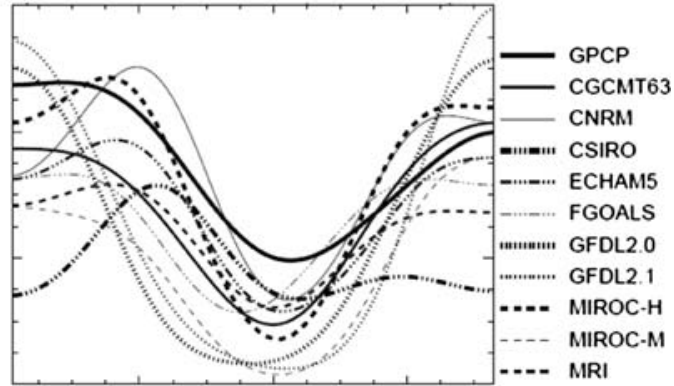

(f) Southern Amazon (10S $\times 55 \mathrm{~W}$ )

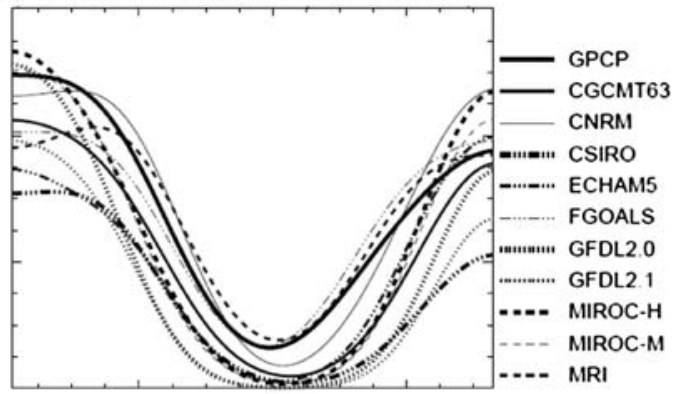

(h) $\mathrm{SACZ}(30 \mathrm{~S} \times 37.5 \mathrm{~W})$

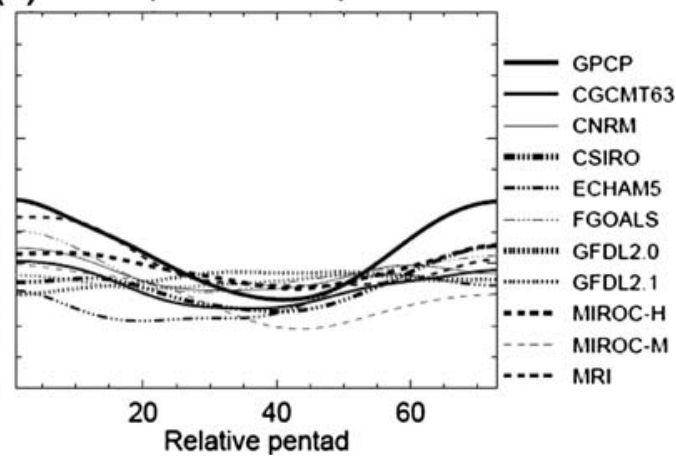


cycle of rainfall for observation and models in distinct areas over tropical SA and over the Atlantic Ocean as indicated by boxes in Fig. 3a. Areas were selected with the objective to verify the ability of the models in simulating distinct precipitation regimes in the following regions: northwest SA $\left(2.5^{\circ} \mathrm{N}, 72.5^{\circ} \mathrm{W}\right)$, Amazon mouth $\left(0.0^{\circ} \mathrm{S}\right.$, $\left.50.0^{\circ} \mathrm{W}\right)$, central Amazon $\left(5.0^{\circ} \mathrm{S}, 60.0^{\circ} \mathrm{W}\right)$, western Amazon $\left(70.0^{\circ} \mathrm{W}, 5.0^{\circ} \mathrm{S}\right)$, southern Amazon $\left(10.0^{\circ} \mathrm{S}, 55.0^{\circ} \mathrm{W}\right)$, central Brazil $\left(17.5^{\circ} \mathrm{S}, 50.0^{\circ} \mathrm{W}\right)$ and the oceanic portion of the SACZ $\left(30.0^{\circ} \mathrm{S}, 37.5^{\circ} \mathrm{W}\right)$. The latter, indicated by the box over subtropical Atlantic (Fig. 3a), corresponds approximately to the region where high variance in daily outgoing long-wave radiation (OLR) is observed in association with the SACZ (e.g. Carvalho et al. 2004). For this discussion, the average annual cycle in each box preserved the original spatial resolution of the models such that we can identify the role of increasing resolution in different versions of the models (as in the case of MIROC3.2-hires and MIROC3.2-medres).

The observed (GPCP) mean annual cycle of precipitation over northwest Amazon (Fig. 3b) shows maximum precipitation in June ( $\sim$ pentad 31$)$ and minimum in January $(\sim$ pentad 1$)$. Figure $3 b$ indicates a large dispersion among IPCC models for the simulation of the mean annual cycle in that region. GFDL-CM2.1 and GFDL-CM2.0, for instance, simulate an annual cycle about 6 months out-ofphase with respect to observations, with minimum precipitation in June and maximum in January. An unrealistic spring and fall peak in the annual cycle is also observed for many models and is more pronounced for MRICGCM2.3.2. MIROC3.2-hires and MIROC3.2-medres capture the correct phase of the annual cycle, although MIROC3.2-hires overestimates (underestimates) precipitation in the rainy (dry) season comparatively to observations. With the exception of MIROC3.2-hires all other models underestimate precipitation in the rainy season. The large dispersion in the results and also the double peak in the annual cycle are likely related to the misrepresentation of the Pacific and Atlantic ITCZ and their seasonal variability in most models investigated here (see Fig. 2).

Near the Amazon mouth (Fig. 3c), western (Fig. 3d) and central (Fig. 3f) Amazon a large dispersion among models for the simulations of the annual cycle of precipitation is also observed. The dispersion decreases and the simulated phase of the annual cycle approaches observation over southern Amazon (Fig. 3g), perhaps as the result of a weaker influence of the ITCZ. Over the Amazon mouth (Fig. 3c) all other models show an out-of-phase maximum of precipitation and underestimate the observed precipitation during the peak of the rainy season.

The dispersion among model simulations of the precipitation annual cycle decreases dramatically over central
Brazil (Fig. 3g) and SACZ (Fig. 3h). All models are capable of correctly identifying the wet and dry seasons over central Brazil (Fig. 3g) where SAMS has its large signal (Silva and Carvalho 2007). However, all models maintain a negative bias during the dry season. During the wet season, different models present either positive or negative bias with respect to observations. Over the oceanic SACZ (Fig. 3h), observations show a low amplitude annual cycle, with minimum precipitation during $\mathrm{SH}$ winter. All models correctly simulate the low seasonal variability, but with amplitudes that are lower than observed. Some models such as GFDL-CM2.0 and GFDLCM2.1 show no seasonal variation in the annual cycle in that region.

\section{SAMS onset, end, duration and total precipitation}

The onset, end and duration of SAMS were estimated for every grid point and for every season by applying the Liebmann and Marengo (2001) method (Eq. 1). The total summer monsoon precipitation was also computed for every season as the total rainfall accumulated between the onset and demise of SAMS. Medians were used to describe the features of the 20CM and A1B experiments to avoid assumptions regarding the actual distributions of the variables and provide information about the central value that is less influenced by extreme values (e.g. Wilks 2006). The onset, demise, duration and total precipitation were computed separately for each simulation of FGOALS-g1.0, MIROC3.2-medres and MRI-CGCM2.3.2, whereas the statistical analyses were performed considering all model simulations together.

\subsection{Total summer monsoon precipitation}

The spatial variability of the median total precipitation during the summer monsoon for GPCP data is shown in Fig. 4a. Large median total precipitation $(>1,600 \mathrm{~mm})$ is observed over the Brazilian Amazon and over the Atlantic and Pacific ITCZ. A local maximum $(>1,800 \mathrm{~mm})$ is observed near the Amazon mouth (Fig. 4a). These observations are consistent with Marengo et al. (2001) and Liebmann and Marengo (2001) that show large total annual rainfall over northeast Amazon and near the Amazon mouth. Liebmann and Marengo (2001) using rain gauge data showed that the annual mean precipitation varies more than $50 \%$ within the Amazon basin with totals of 2,000 mm over south, east and north of the Amazon, and 3,000 mm over northwest Amazon, where relatively high topography is observed. They also identified a secondary maximum near the Amazon mouth, which they have related to the nocturnal convergence of the trade winds with 
Fig. 4 Median total

precipitation during the rainy season for a GPCP;

b CGCM3.1(T63); c CNRMCM3; d CSIRO-Mk3.0; e ECHAM5; f FGOALS-g1.0; g GFDL-CM2.0; h GFDL-

CM2.1; i MIROC3.2-hires; j MIROC3.2-medres and k MRI-CGCM2.3.2. Contour interval equals $200 \mathrm{~mm}$. Light gray shading shows regions with $1200 \mathrm{~mm} \leq$ median < $1,600 \mathrm{~mm}$ and dark gray shading shows regions with median $\geq 1,600 \mathrm{~mm}$ (a) Median TotPrec (GPCP)

(b) CGCMT63 (20CM)

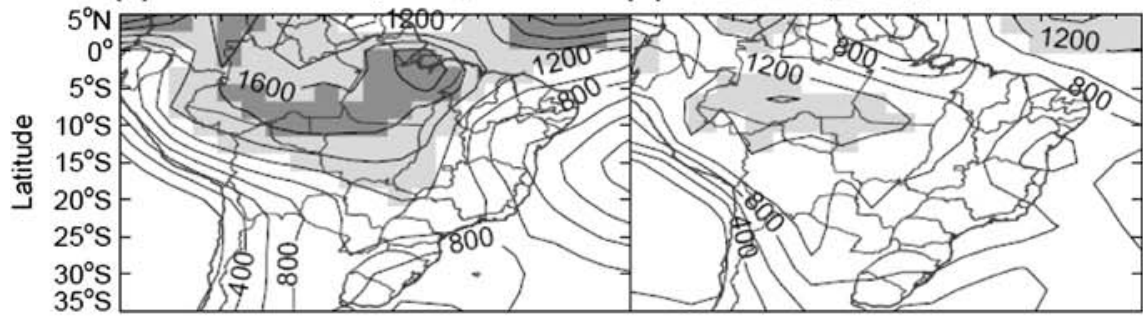

(c) CNRM (20CM)

(d) $\operatorname{CSIRO}(20 \mathrm{CM})$

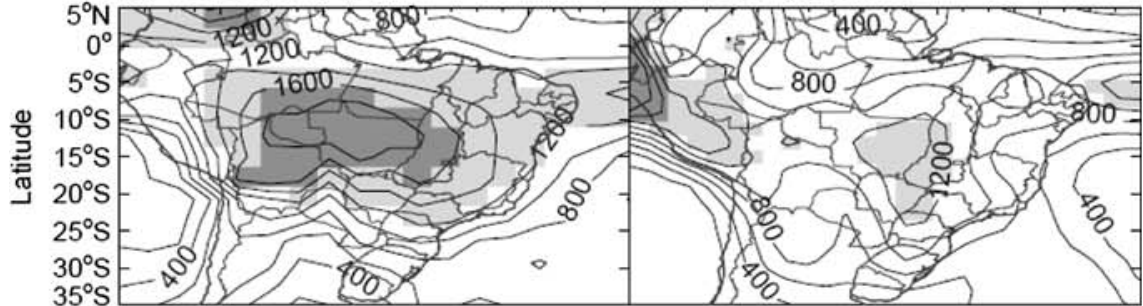

(e) ECHAM5 (20CM)

(f) FGOALS (20CM)

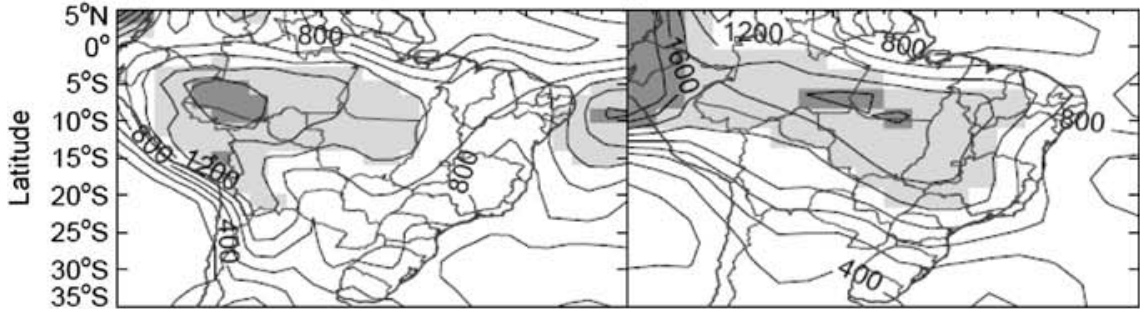

(g) GFDL2.0 (20CM)

(h) GFDL2.1 (20CM)

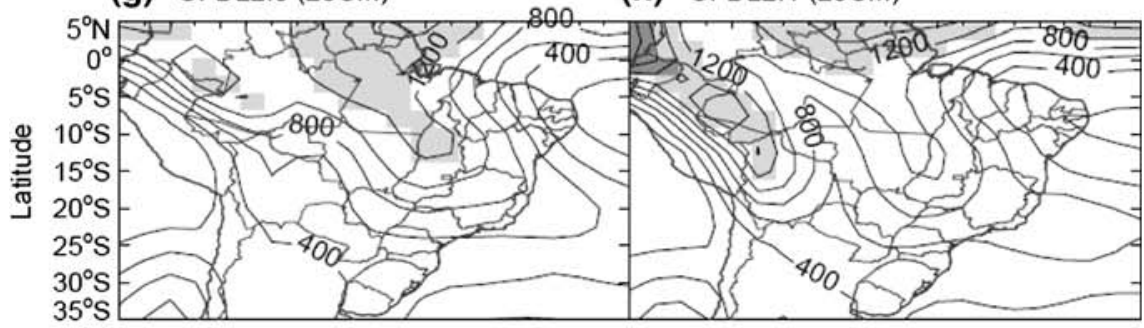

(i) MIROC-H (20CM)

(j) MIROC-M (20CM)
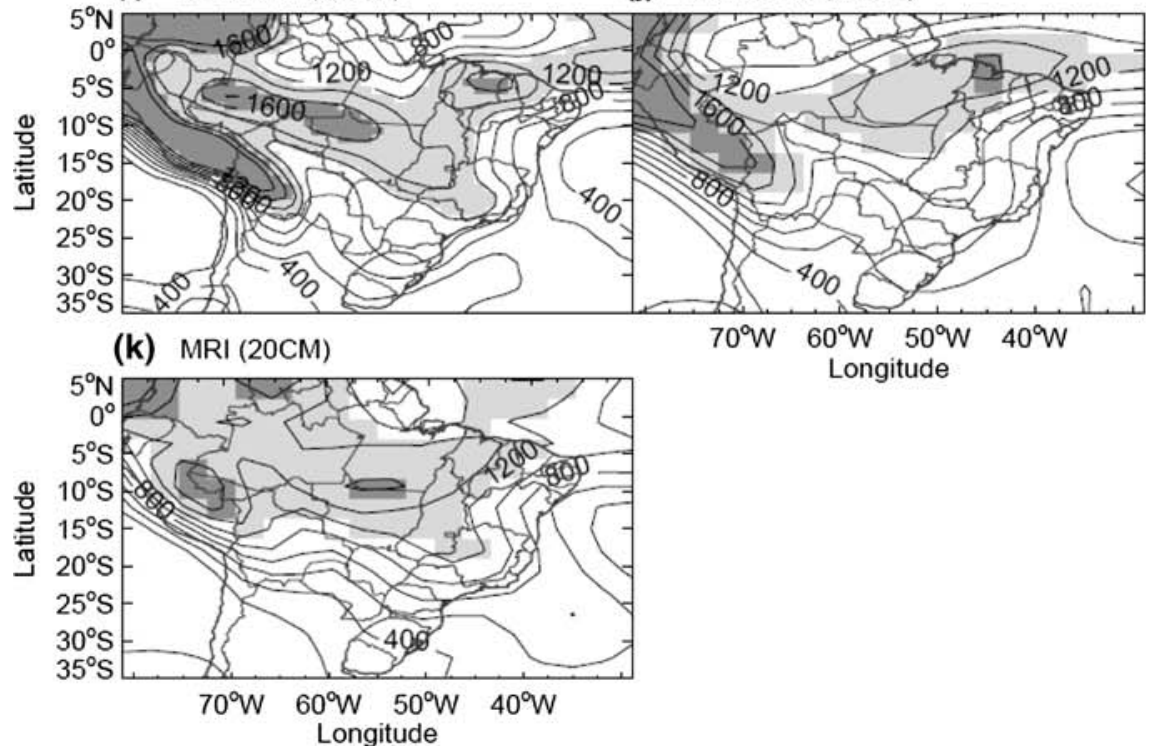
the sea breeze. Over central Brazil, the median precipitation decreases, with totals between 1,000 and $1,400 \mathrm{~mm}$. The southeastward displacement of the 1,200 and $800 \mathrm{~mm}$ isohyets indicates the importance of the SACZ.

For the 20CM simulations, large discrepancies are observed over the Amazon (Fig. 4b-k) as diagnosed in previous studies (Sun et al. 2005; Dai 2006; Vera et al. 2006b). For instance, CGCMT63 (Fig. 4b) underestimates in about $400 \mathrm{~mm}$ and CSIRO-Mk3.0 (Fig. 4d) in more than $600 \mathrm{~mm}$ the total median precipitation over the entire Amazon. In addition CSIRO-Mk3.0 displaces the maximum precipitation $(\sim 1,200 \mathrm{~mm})$ toward central Brazil. CNMR (Fig. 4c) and ECHAM5 (Fig. 4e) are not capable of correctly identifying the precipitation regime over northeast Brazil (known as "nordeste") and distinguish it from SAMS and ITCZ, which results in unrealistic large summer precipitation in that region. Moreover, CNRM-CM3 (Fig. 4c) overestimates precipitation over central Brazil by about $600 \mathrm{~mm}$. Both GFDL-CM2.0 (Fig. 4g) and GFDLCM2.1 (Fig. 4h) show a very poor representation of the total summer monsoon precipitation. MIROC3.2hires (Fig. 4i) simulates the maximum precipitation $(>1,600 \mathrm{~mm})$ over western Amazon around its actual position (Fig. 4a) and shows a secondary maximum over northern Brazil, displaced eastward from the maximum observed with GPCP over the Amazon mouth. MIROC3.2medres (Fig. 4j) shows a good representation of the actual pattern of the summer monsoon precipitation. MRICGCM2.3.2 (Fig. 4k) realistically represents the total precipitation over northeast Brazil and captures the main spatial features of SAMS.

\subsection{Variability of the summer monsoon precipitation}

The ability of each model to capture the actual variability of the rainfall is essential to assess possible climate changes in future scenarios. This issue was investigated here by computing the median absolute deviation (MAD), which measures the residuals (deviations) from the data median and is defined as:

$\operatorname{MAD}=\operatorname{median}\left(\left|y_{i t}-\tilde{y}_{i}\right|\right)$,

where $y_{i t}$ is the total summer monsoon precipitation for the year $t$ at a given grid point $i$ and $\tilde{y}_{i}$ is the median of the summer monsoon precipitation at the same grid point. MAD provides a good measure of the scale parameter of unknown distributions in substitution to standard deviations and is less affected by extremes (Wilks 2006).

Figure 5 shows MAD for the simulations of the total summer monsoon precipitation discussed in Fig. 4. Large (small) MAD can be interpreted as regions with high (low) interannual variability of SAMS precipitation. Large interannual variability in precipitation $(>200 \mathrm{~mm})$ is observed with GPCP data (Fig. 5a) over northern SA and southern Brazil, Uruguay, and northeast Argentina. This pattern of interannual variability is consistent with the modulation of precipitation by ENSO phenomenon (e.g. Grimm et al. 2000; Coelho et al. 2002; Magaña and Ambrizzi 2005) on interannual timescales. Relatively low interannual variability $(<200 \mathrm{~mm})$ is observed over central SA, where large seasonal variations of precipitation, lowlevel circulation and humidity are observed in association with SAMS (Silva and Carvalho 2007). In addition, low interannual variations occur over subtropical Atlantic and Pacific near the west coast of SA.

CNRM-CM3 (Fig. 5c) is the only model that simulates high interannual variability of total precipitation $(>200 \mathrm{~mm})$ in association with the model's SACZ (compare with Fig. 2c). All other models show relatively low variability of precipitation in association with the SACZ and over the SAMS core in center Brazil (Silva and Carvalho 2007). MIROC3.2-hires (Fig. 5i) shows the most realistic pattern of MAD over SA. MIROC3.2-medres (Fig. 5j) shows less interannual variability $(<200 \mathrm{~mm})$ in basically all SA, with the exception of a small area over the Amazon and central east Brazil. All models tend to increase the interannual variability of precipitation over northern SA and ITCZ likely as a response to the model's ENSO. Nevertheless, only ECHAM5 (Fig. 5e) and MIROC3.2-hires (Fig. 5i) show a large MAD over southern Brazil in agreement with observations (Fig. 5a).

\subsection{SAMS onset}

The present analysis investigates the spatial variability of the median SAMS onset over tropical SA. For this purpose, the onset is schematically indicated with arrows in Fig. 6. The direction of the arrows indicates the period of the year when the onset occurs for a given grid point according to the circle at the bottom of Fig. 6. The GPCP data indicates that over central and southeast Brazil, the median onset is observed between pentads 58-61 (approximately mid to end of October, respectively), consistent with Silva and Carvalho (2007) (Fig. 6a). The median onset date varies rapidly toward northern $\mathrm{SA}$, with the rainy season beginning between early November to late December, in agreement with observations in Liebmann and Marengo (2001), Lincoln et al. (2005) and Seth et al. (2007). Most IPCC models simulate correctly the median onset between pentad 58 and 61 over central Brazil (Fig. 6b-k). The overall agreement among models is consistent with the observation that the phase of the annual cycle is well captured by all models over this region (Fig. 3g). Nevertheless, over southeast Brazil, where the SACZ manifests, there is a larger dispersion among models, with simulated onsets varying from early October to late November 
Fig. 5 MAD of total

precipitation during the rainy season for a GPCP;

b CGCM3.1(T63); c CNRMCM3; d CSIRO-Mk3.0; e ECHAM5; f FGOALS-g1.0; g GFDL-CM2.0; h GFDL-

CM2.1; i MIROC3.2-hires;

j MIROC3.2-medres and k MRI-CGCM2.3.2. Contour interval is equal to $100 \mathrm{~mm}$. Light gray shading shows regions where

$100 \mathrm{~mm} \leq \mathrm{MAD}<200 \mathrm{~mm}$
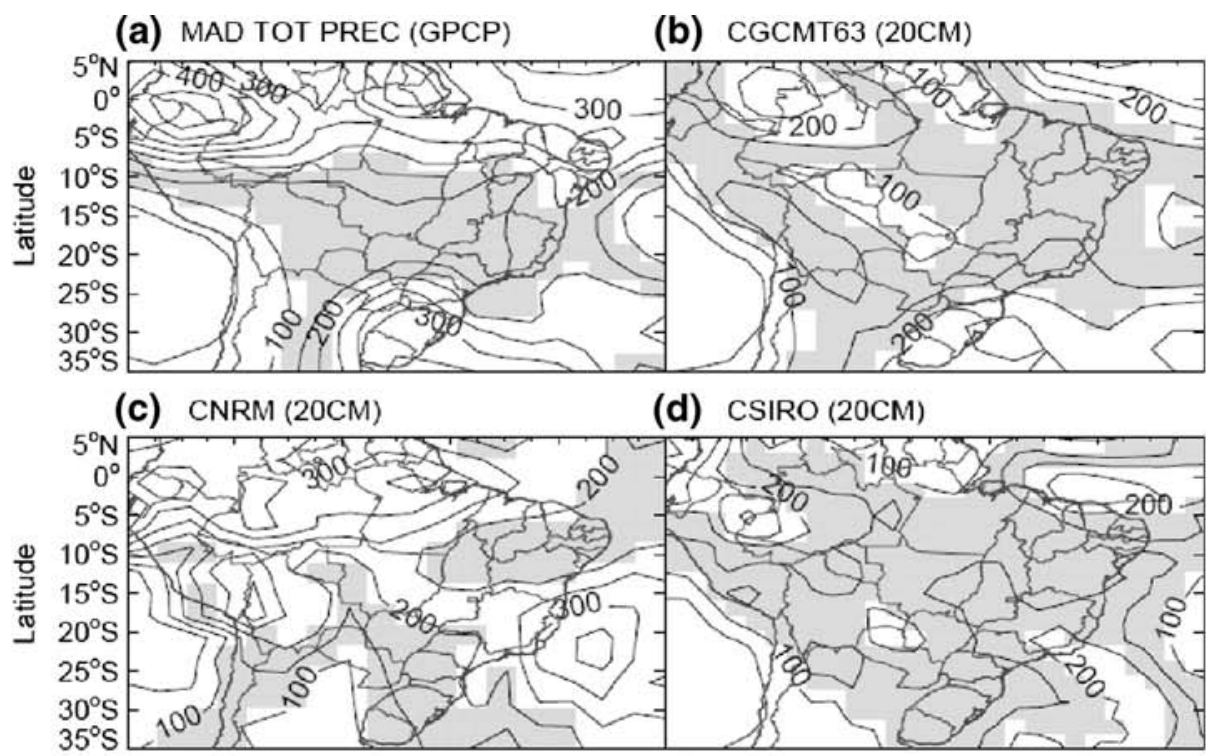

(e) ECHAM5 (20CM)

(f) FGOALS (20CM)

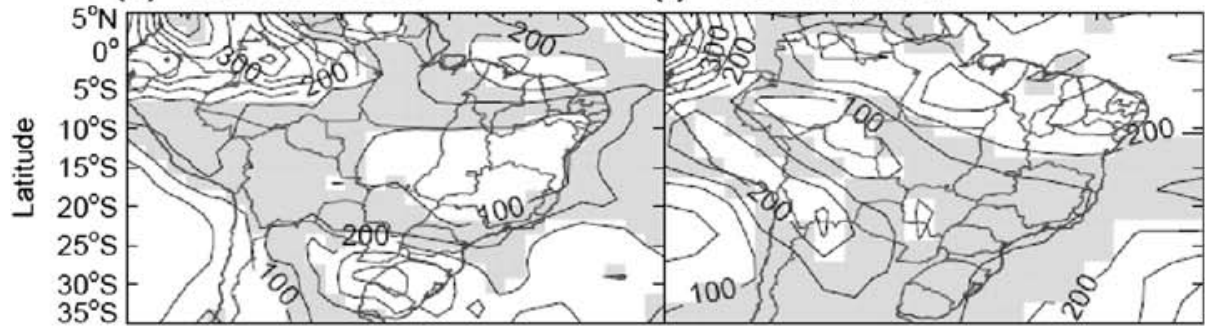

(g) GFDL2.0 (20CM)

(h) GFDL2.1 (20CM)

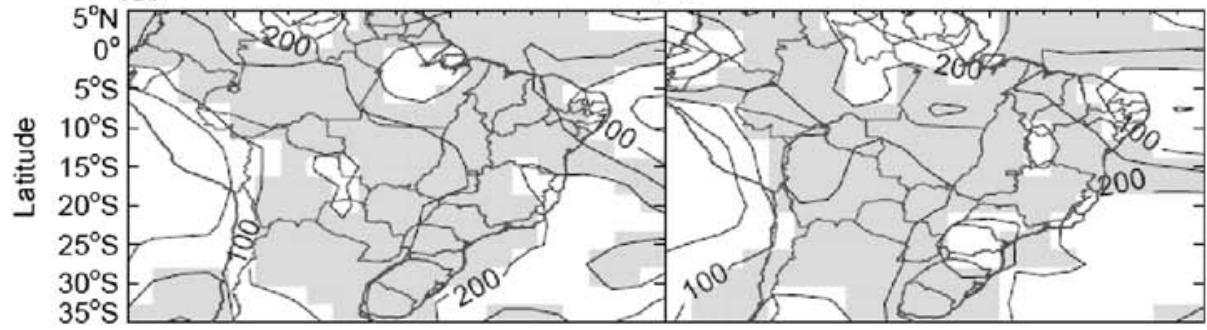

(i) MIROC-H (20CM)

(j) MIROC-M (20CM)
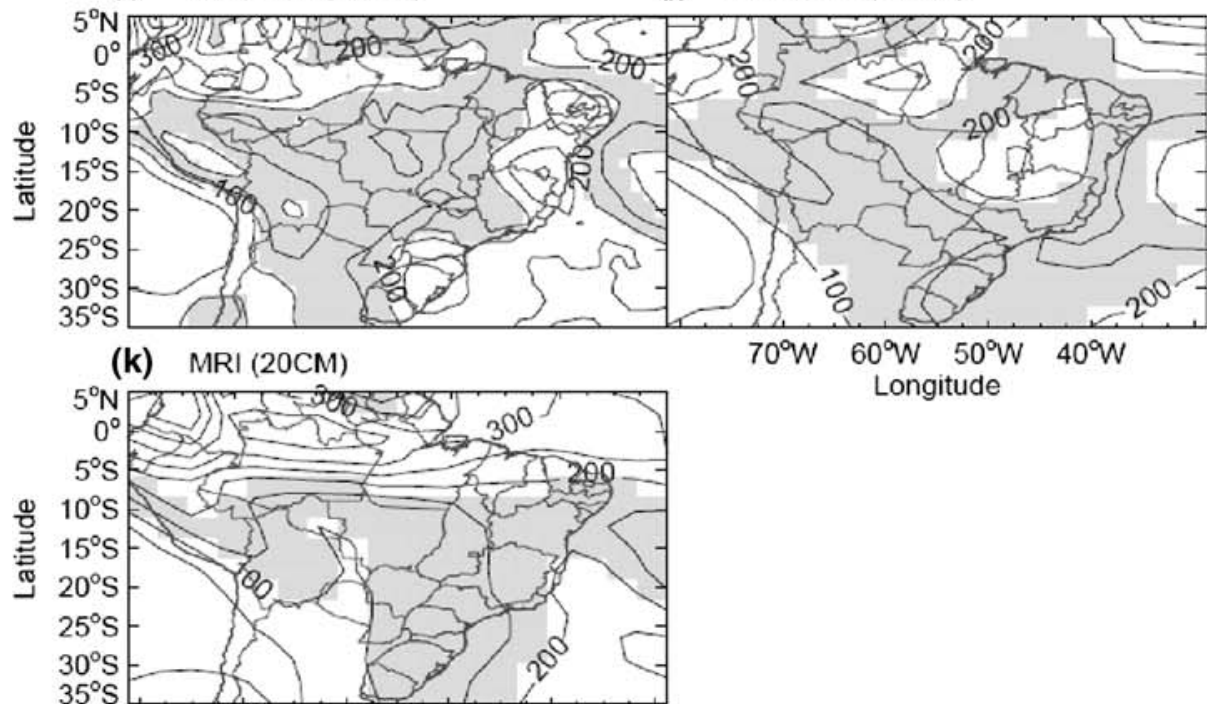
Fig. 6 Median onset of the rainy season for a GPCP; b CGCM3.1(T63); c CNRMCM3; d CSIRO-Mk3.0; e ECHAM5; f FGOALS-g1.0; g GFDL-CM2.0; h GFDLCM2.1; i MIROC3.2-hires; j MIROC3.2-medres; k MRICGCM2.3.2. Arrows indicate the time of the year when the onset occurs, according to the circle indicated at the bottom of the figure. The size of the arrows varies only due to the resolution of the model and has no meaning. Shading indicates regions where the median onset date is greater than pentad 58 (13-17 October) and less than pentad 62 (2-6 November) (a) Onset Median (GPCP)

(b) $\operatorname{CGCMT63~(20CM)~}$

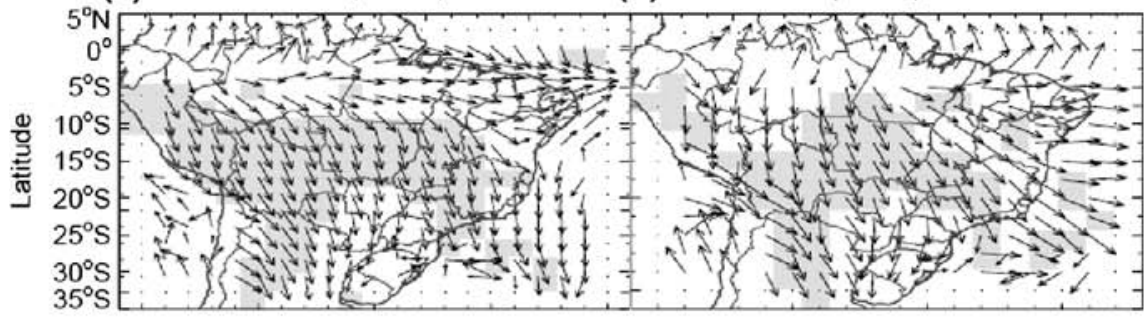

(c) $\operatorname{CNRM}(20 \mathrm{CM})$

(d) $\operatorname{CSIRO}(20 \mathrm{CM})$

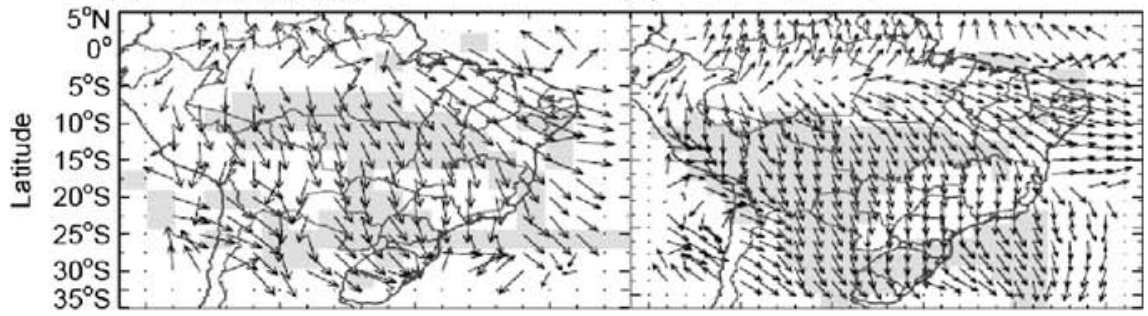

(e) ECHAM5 (20CM)

(f) FGOALS (20CM)

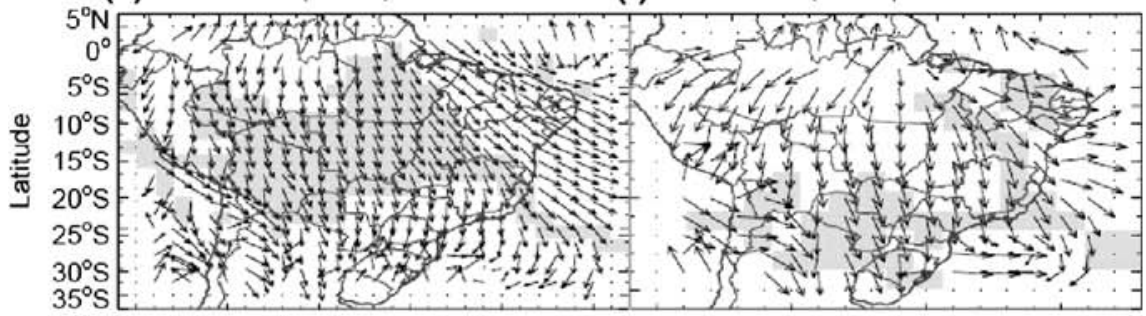

(g) GFDL2.0 (20CM)
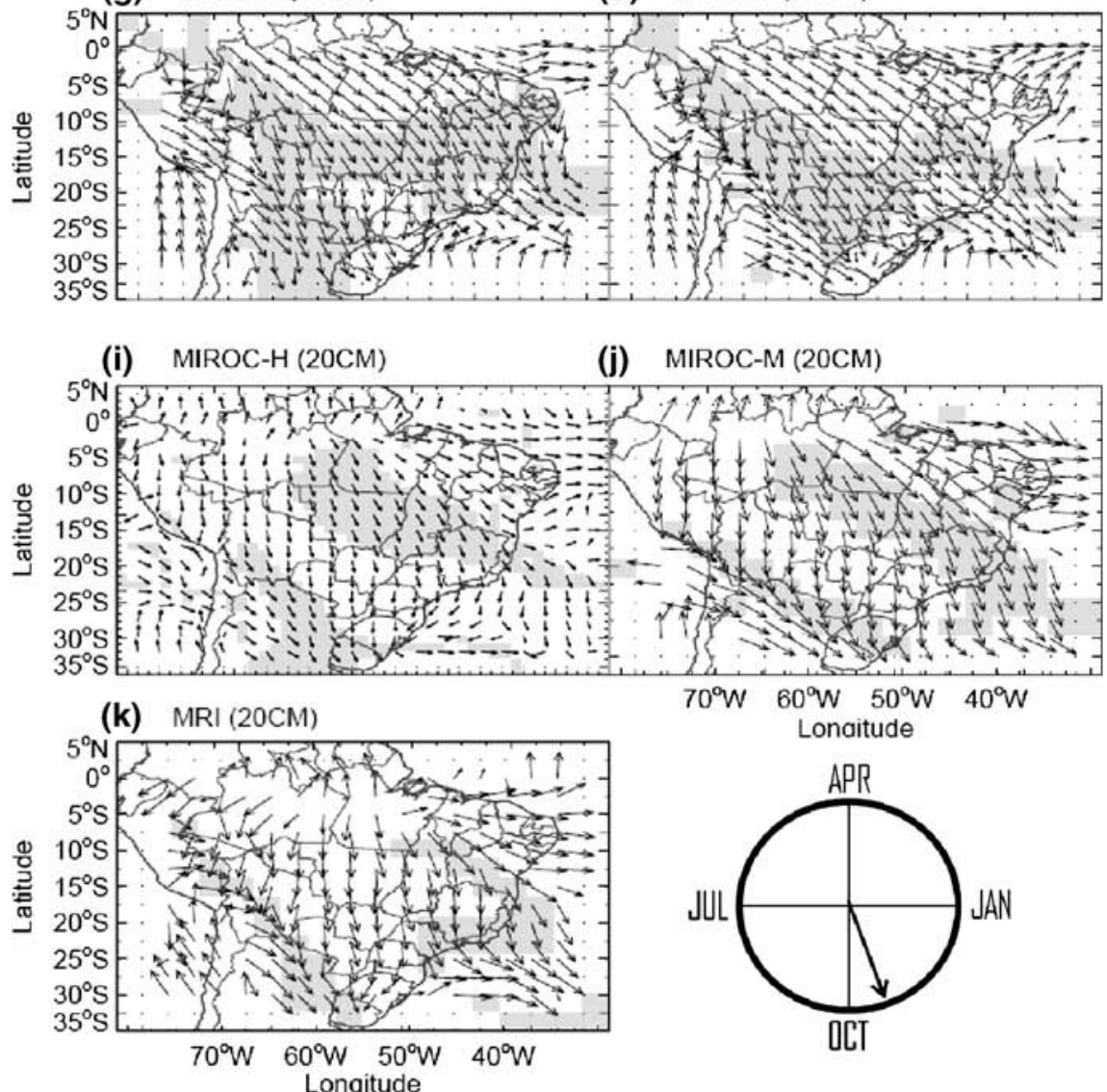
(i.e. pentad 56-64). Furthermore, this analysis emphasizes the misrepresentation of the actual onset of the monsoon over north and western Amazon and near the Amazon mouth as suggested by the annual cycles in Fig. 3b-d, respectively.

A good performance of some models in simulating the actual median precipitation does not imply a good representation of SAMS onset. For instance, MIROC3.2-hires shows one of the most realistic representations of SAMS median precipitation features (Fig. 4i). However, this model shows early onsets (between pentad 56 and 58) from south Amazon toward southeast Brazil, in addition to a fairly unrealistic representation of onsets over northern Amazon (Fig. 6i). On the other hand, ECHAM5 does not correctly simulate the SACZ and underestimates SAMS precipitation (Fig. 4e), but captures the onset of the rainy season over central Brazil (Fig. 6e). FGOALS-g1.0 (Fig. 6f), and MRI-CGCM2.3.2 (Fig. 6k) show the earliest onsets for the rainy season over central Amazon and southeastern Brazil (between pentad 56 and 58).

A remarkable unrealistic representation of the onset of the rainy season over north Amazon by all IPCC models is clearly evident (compare Fig. 6a with Fig. 6b-k). For instance, the out-of-phase onsets of the rainy season over north Amazon (Fig. 3b) and over the Amazon mouth (Fig. 3c) in models such as GFDL-CM2.0 and GFDLCM2.1 appears as a large feature over northern SA (Fig. 6g, h).

The interannual variability of onsets is examined here by computing MAD (Eq. 2) and replacing total precipitation with the onset dates (Fig. 7). The GPCP data (Fig. 7a) indicate that from 1979 to 2006 the onset of the monsoon over central Brazil showed median variability of about two pentads. MAD increases to four pentads over northern Amazon, southern Brazil and Atlantic SACZ. Large MAD is observed over northern Amazon and southern Brazil, Uruguay and northeastern Argentina (Fig. 7a), likely as a response to ENSO. Most IPCC models show small MAD over central Brazil (Fig. 7b-k). In general, most IPCC models tend to increase MAD over north-northwest SA in association with interannual variations in the model's ITCZ. Large variations are also observed over the subtropics of SA. Among all models, MIROC3.2-hires (Fig. 7i) and MRI-CGCM2.3.2 (Fig. 7k) show patterns of the onset MAD that are the most consistent with observations over central Brazil (compare with Fig. 7a).

\subsection{SAMS demise and duration}

The median end of the rainy season (Eq. 1) over central and southeast Brazil occurs between pentad 18-21 (end March to mid-April) as intense precipitation gradually migrates from south Amazon and central Brazil toward the equator (Kousky 1988; Marengo et al. 2001; Gan et al.
2004; Vera et al. 2006a; Silva and Carvalho 2007) (not shown). During SAMS demise, convection associated with the Atlantic ITCZ weakens (Vera et al. 2006a). Due to the simulation of a stronger than observed and/or double ITCZ, the IPCC models tend to simulate early demises of the rainy season over northeast Brazil (between 4 and 6 pentads, not shown). CSIRO-Mk3.0, for instance, indicates the demise of the rainy season as early as four pentads over central Brazil. GFDL-CM2.0 and FGOALS-g1.0 show relatively less difference, between -1 and 1 pentad over the same region, although both GFDL-CM2.0 and GFDLCM2.1 do not realistically simulate the pattern of demise dates over SA, showing basically the same dates for the north and central Brazil regions.

The median duration of SAMS observed with GPCP (Fig. 8a) is between 32 and 36 pentads over most SA, with long durations toward the center of the continent. The IPCC simulations for the present climate tend to overestimate the duration of the rainy season over west SA and underestimate over central Brazil (Fig. 8). Models such as FGOALS-g1.0 (Fig. 8f), MIROC3.2-hires (Fig. 8i) and MRI-CGCM2.3.2 (Fig. 8k) are skillful in representing the patterns of duration of the rainy season over tropical SA, with less difference with respect to observation over Central Brazil (between 0 and 2 pentads). On the other hand, GFDL-CM2.0 (Fig. 8g) and GFDL-CM2.1 (Fig. 8h) show the worst performance in simulating the patterns of duration of SAMS, underestimating the duration of the monsoon in about four pentads over central Brazil.

Median absolute deviation computed for SAMS duration is shown in Fig. 9. We recall that the duration of the rainy season depends on the onset and demise of the season and MAD quantifies the yearly variations of these quantities. The duration of the rainy season based on GPCP data (Fig. 9a) shows less variability over central tropical SA (24 pentads). In general, MAD over the core of monsoon region (Silva and Carvalho 2007) is below four pentads for all models. MIROC3.2-hires (Fig. 9i), MIROC3.2-medres (Fig. 9j) and MRI-CGCM2.3.2 (Fig. 9k) show the most realistic spatial patterns of MAD over central Brazil compared to observations. The largest differences between observation and simulations of SAMS duration is simulated by ECHAM5 (Fig. 9e) and FGOALS-g1.0 (Fig. 9f), which underestimate the interannual variability over tropical SA, whereas GFDL-CM2.0 and GFDL-CM2.1 (Fig. 9h) overestimate the variability.

\section{Summary of SAMS Simulation in the 20CM scenario}

To objectively evaluate the skill of the IPCC models in reproducing SAMS spatial pattern of the median and 
Fig. 7 Same as in Fig. 5, but for MAD of onset of the rainy season. Line interval is equal to two pentads. Light gray shading shows regions where two pentads $<$ MAD $\leq$ four pentads and greater than two pentads and dark gray shading shows regions where MAD $\leq 2$ pentads

(a) MAD ONSET (GPCP)

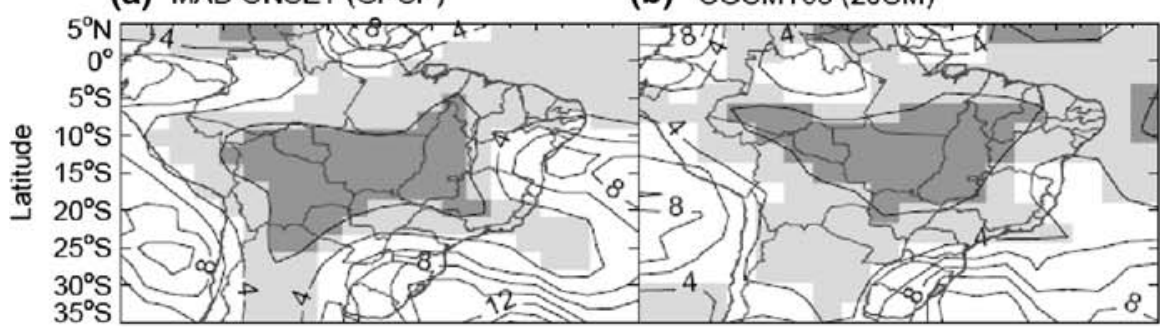

(c) $\operatorname{CNRM}(20 \mathrm{CM})$

(d) CSIRO (20 CM)

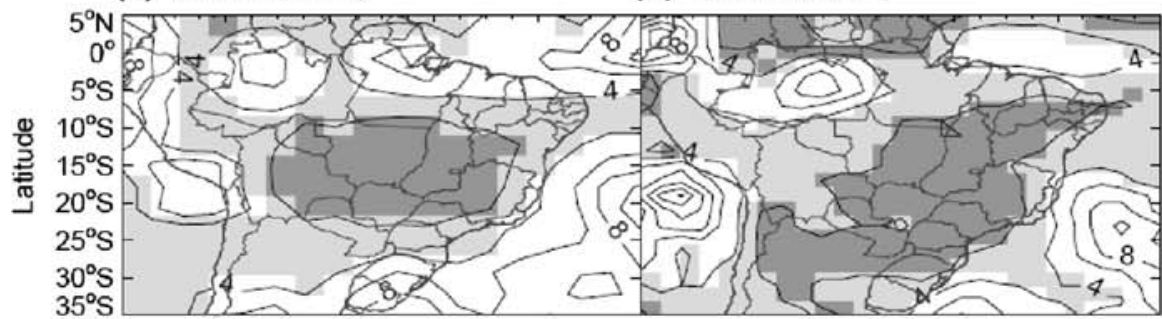

(e) ECHAM5 (20CM)

(f) FGOALS (20CM)

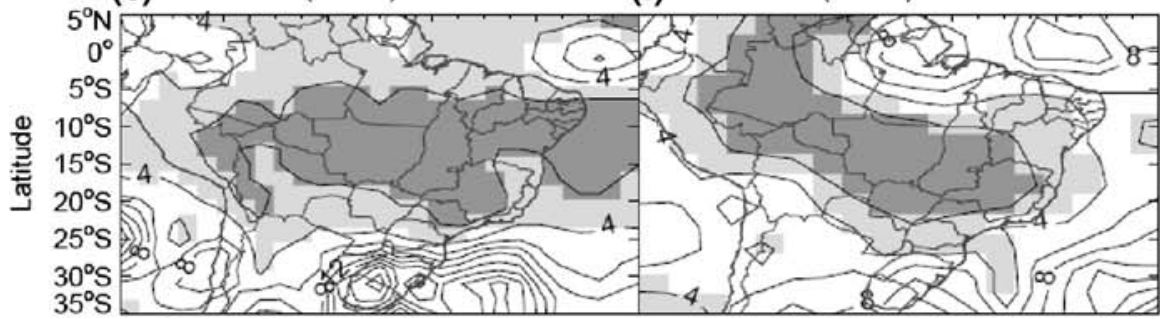

(g) GFDL2.0 (20CM)

(h) GFDL2.1 (20CM)

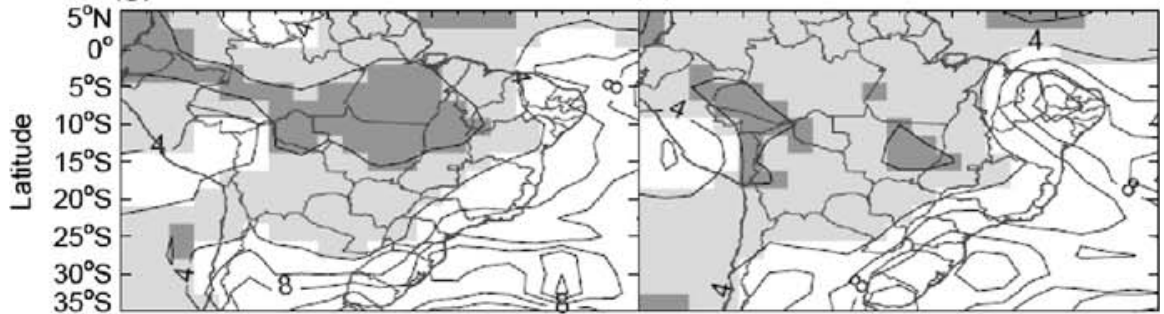

(i) MIROC-H (20CM)

(j) MIROC-M (20CM)
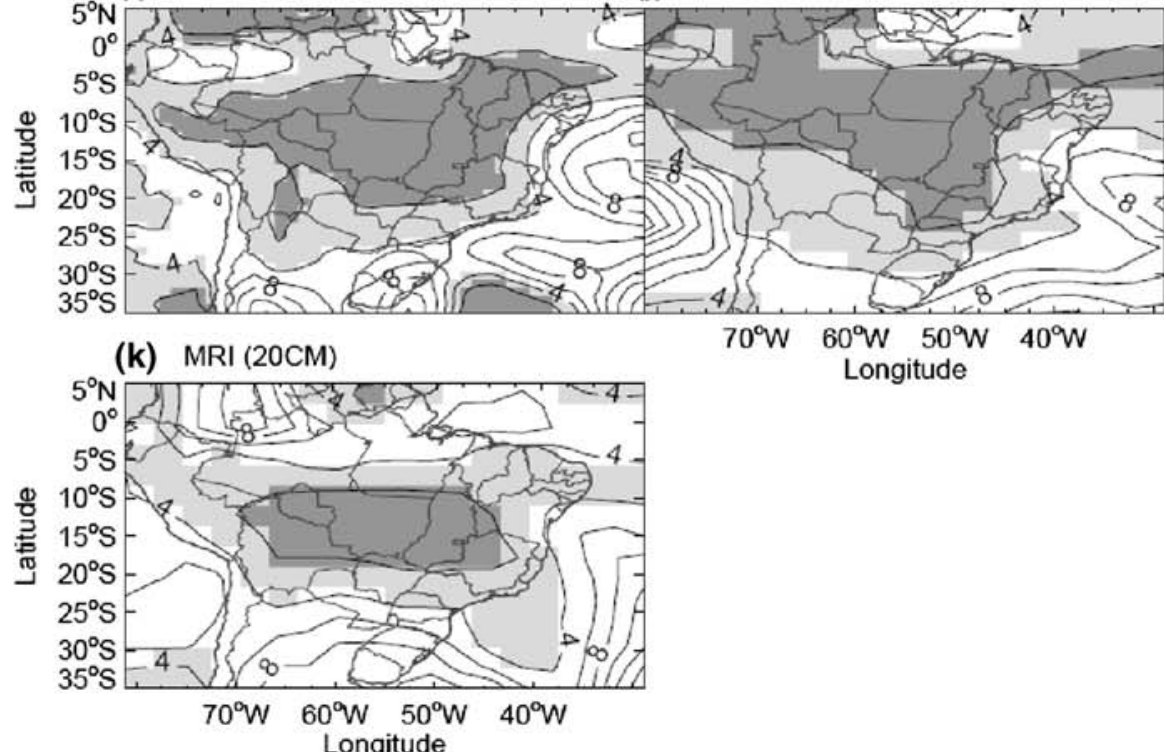
Fig. 8 Same as in Fig. 4, but for median of duration of the rainy season. The line interval is equal to two pentads. Light gray shading shows regions where 32 pentads $\leq$ median $<36$ pentads and the dark gray shading shows regions with median $\geq 36$ pentads
(a) Median Duration (GPCP)
(b) CGCMT63 (20CM)
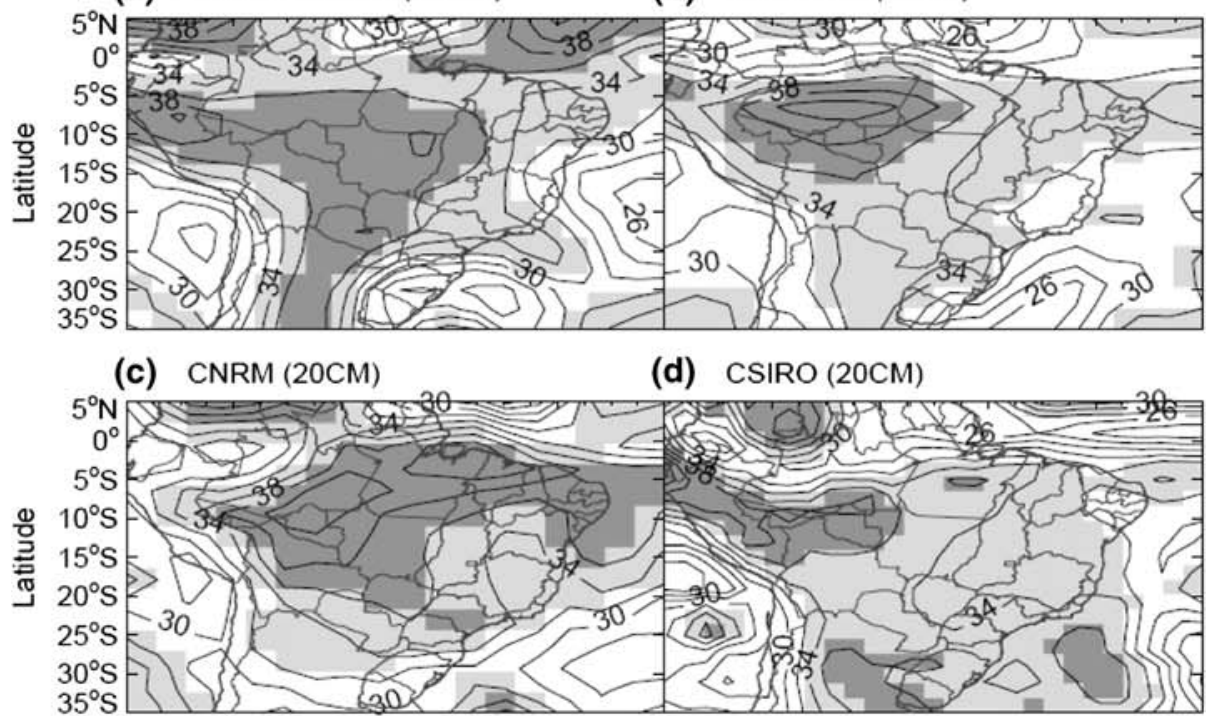

(e) $\operatorname{ECHAM} 5(20 \mathrm{CM})$

(f) FGOALS (20CM)
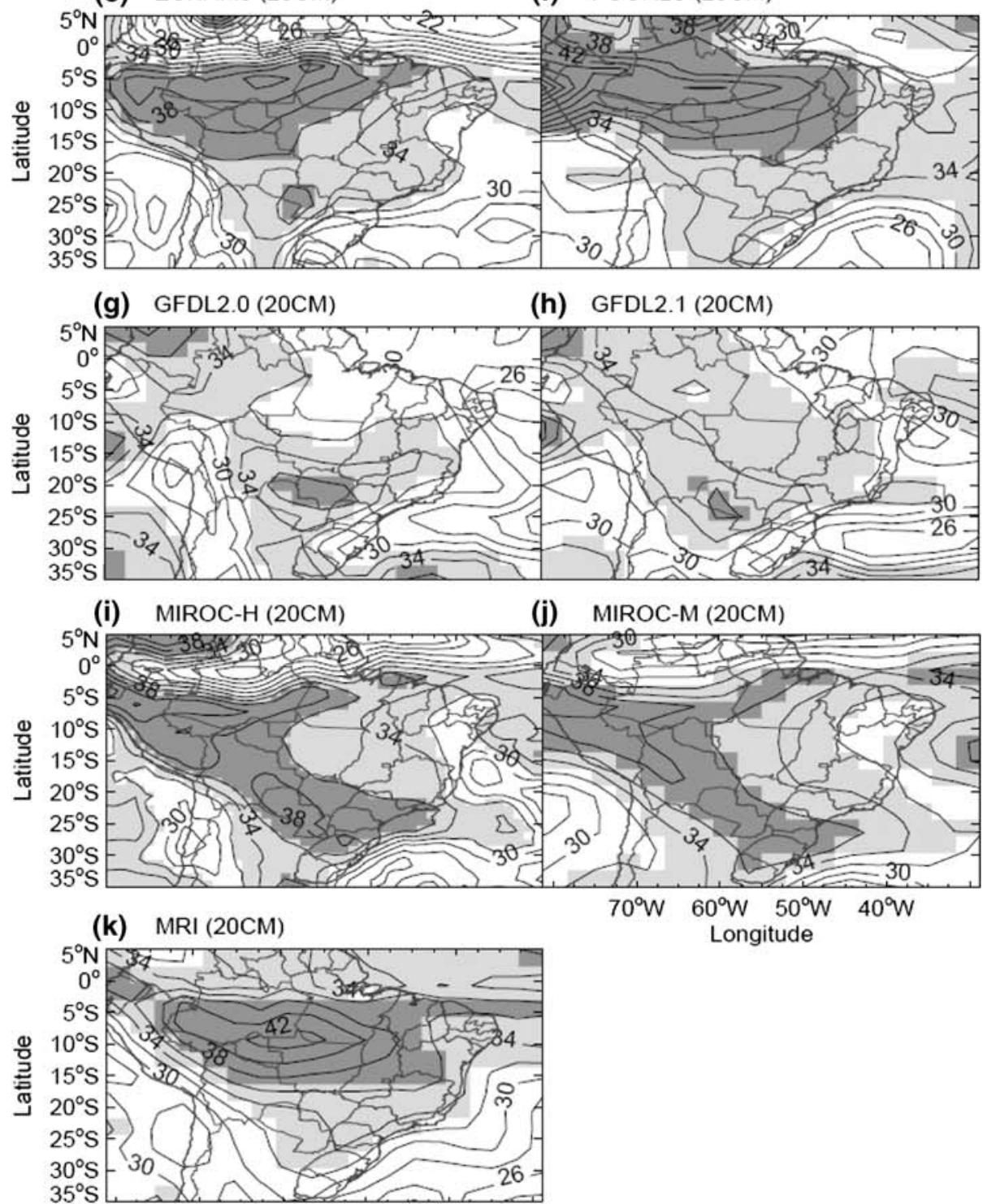
Fig. 9 Same as in Fig. 5, but for MAD of duration of the rainy season. Contour interval is equal to two pentads. Light gray shading shows regions where two pentads $<$ MAD $\leq$ four pentads dark gray shading shows regions where the MAD $\leq$ two pentads

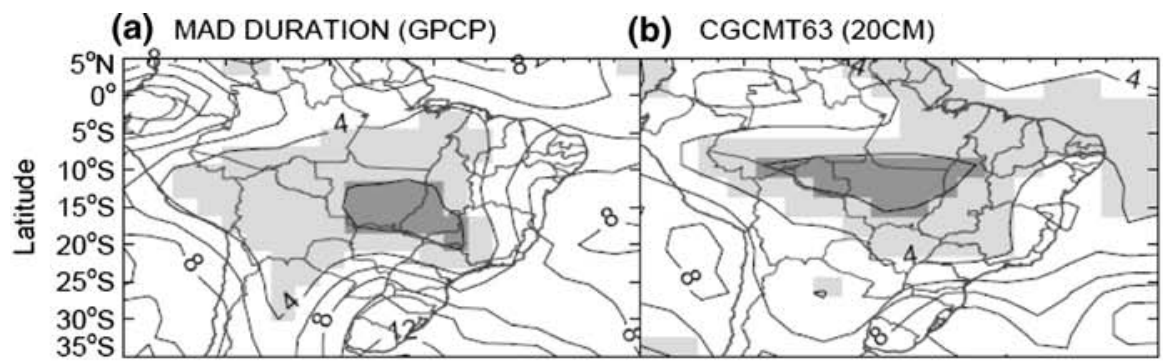

(c) CNRM (20CM)

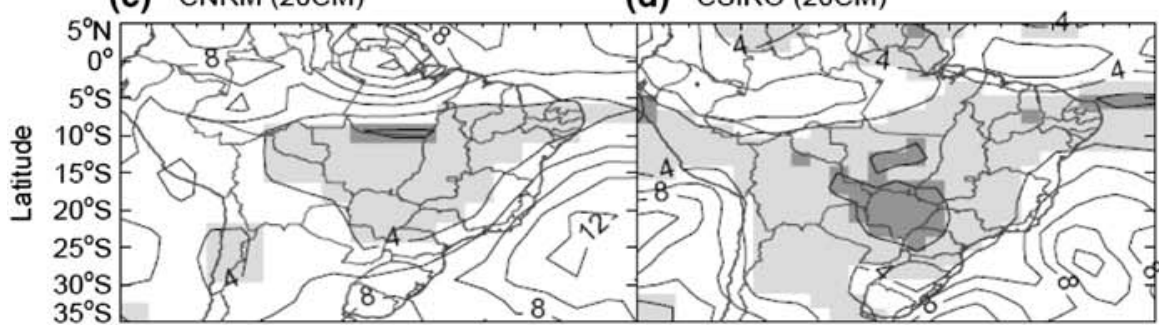

(e) ECHAM5 (20CM)

(f) FGOALS (20CM)

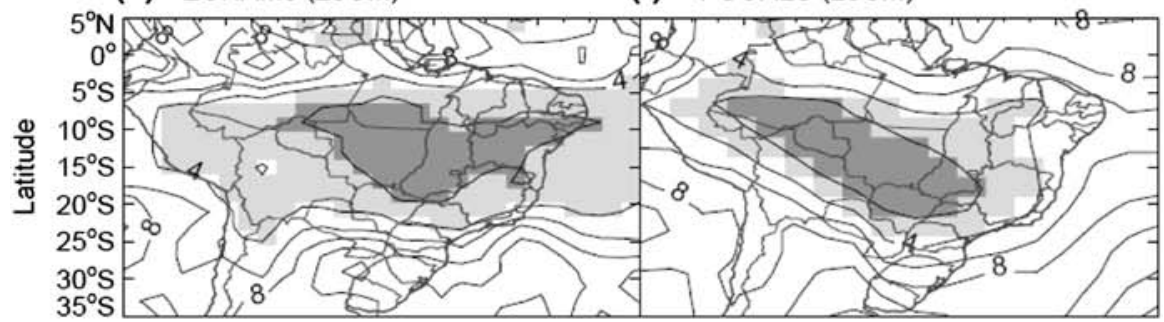

(g) GFDL2.0 (20CM)

(h) GFDL2.1 (20CM)

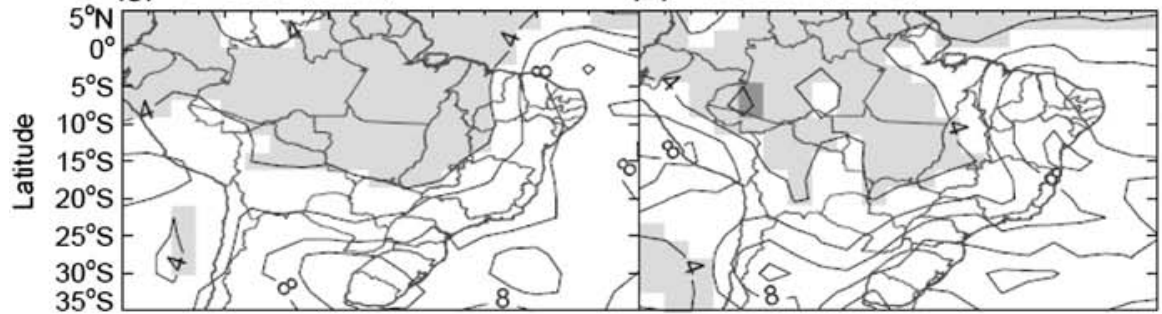

(i) MIROC-H (20CM)

(j) MIROC-M (20CM)
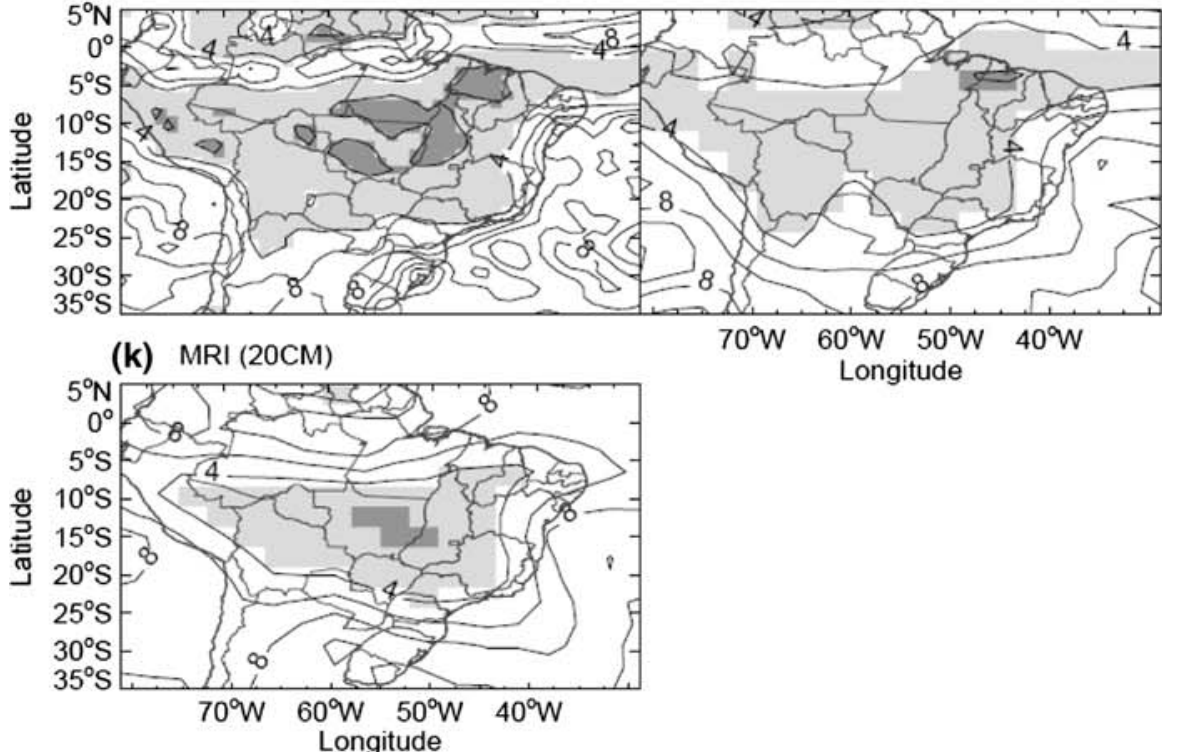
respective MAD of onset, demise, duration and total precipitation in the 20CM simulations, spatial correlation (SC) and spatial root mean square error (RMSE) between model simulations and GPCP were computed. The SC is used as a measure of the spatial co-variability between IPCC model simulations and GPCP. The spatial RMSE indicates the average absolute error between the median and MAD simulations and GPCP and complements the SC analysis. For this purpose, the 20CM maps of median and MAD onset, demise, duration, and total precipitation for both GPCP and IPCC models were re-gridded to a common latitude/longitude resolution. In the cases where models have finer resolution than GPCP, models median and MAD were re-gridded to a $2.5^{\circ}$ latitude/longitude resolution; otherwise, GPCP median and MAD were re-gridded to a $2.8^{\circ}$ latitude/longitude resolution. The domain used in this analysis extends from $23.5^{\circ} \mathrm{S}-7.5^{\circ} \mathrm{S}$ to $62.5^{\circ} \mathrm{W}-25.0^{\circ} \mathrm{W}$, which corresponds approximately to the region where SAMS and SACZ have their maximum variability (Silva and Carvalho 2007). This domain does not include the
Andes to avoid comparisons with the unrealistic precipitation patterns simulated in these high elevations by all models (Marengo 2003). In addition, it was intentionally positioned southward of the climatological position of the ITCZ indicated by GPCP (e.g. Fig. 3a) due to the misrepresentation of this convergence zone by most models. The total number of grid points in these analyses is 72 (91) for the coarser (finer) resolution. Table 2 summarizes the results.

High SC (i.e. SC above 0.7) is observed for the large majority of models for the median onset and demise. However, lower SC is observed for duration, with only two models (MRI-CGCM2.3.2 and ECHAM5) indicating values above 0.7 ( $\mathrm{SC} \sim 0.71$ and 0.74 , respectively). High SC $(>0.7)$ is observed for total precipitation for most models, with the worst performance observed for ECHAM5 (SC 0.15). MIROC3.2-hires shows the best skill in reproducing the spatial patterns of total precipitation (SC $\sim 0.92$ ) followed by MIROC3.2-medres (SC 0.90) and MRI-CGCM2.3.2 (SC 0.83). Nevertheless, large

Table 2 Spatial correlation (top) and spatial RMSE (bottom) between IPCC models simulation and GPCP for median (right) and MAD (left) of onset, demise, duration, and total precipitation

\begin{tabular}{|c|c|c|c|c|c|c|c|c|}
\hline \multirow[t]{2}{*}{ Model } & \multicolumn{4}{|c|}{ Spatial correlation (median) } & \multicolumn{4}{|c|}{ Spatial correlation (MAD) } \\
\hline & $\begin{array}{l}\text { Onset } \\
\text { (pentads) }\end{array}$ & $\begin{array}{l}\text { Demise } \\
\text { (pentads) }\end{array}$ & $\begin{array}{l}\text { Duration } \\
\text { (pentads) }\end{array}$ & $\begin{array}{l}\text { Total precipitation } \\
(\mathrm{mm})\end{array}$ & $\begin{array}{l}\text { Onset } \\
\text { (pentads) }\end{array}$ & $\begin{array}{l}\text { Demise } \\
\text { (pentads) }\end{array}$ & $\begin{array}{l}\text { Duration } \\
\text { (pentads) }\end{array}$ & $\begin{array}{l}\text { Total precipitation } \\
(\mathrm{mm})\end{array}$ \\
\hline CGCM3.1(T63) & 0.834 & 0.441 & 0.660 & 0.798 & 0.531 & 0.517 & 0.577 & 0.269 \\
\hline CNRM-CM3 & 0.788 & 0.434 & 0.415 & 0.762 & 0.546 & 0.314 & 0.609 & 0.087 \\
\hline CSIRO-Mk3.0 & 0.785 & 0.671 & 0.577 & 0.830 & 0.252 & 0.486 & 0.621 & 0.322 \\
\hline ECHAM5 & 0.926 & 0.673 & 0.738 & 0.153 & 0.163 & 0.269 & 0.232 & -0.151 \\
\hline FGOALS-g1.0 & 0.788 & 0.765 & 0.509 & 0.841 & 0.581 & 0.269 & 0.656 & 0.180 \\
\hline GFDL-CM2.0 & 0.872 & 0.741 & 0.432 & 0.631 & 0.394 & 0.398 & 0.649 & 0.128 \\
\hline GFDL-CM2.1 & 0.884 & 0.835 & 0.275 & 0.706 & 0.445 & 0.368 & 0.582 & 0.004 \\
\hline MIROC3.2-hires & 0.806 & 0.720 & 0.561 & 0.921 & 0.609 & 0.500 & 0.816 & 0.591 \\
\hline MIROC3.2-medres & 0.903 & 0.805 & 0.375 & 0.903 & 0.547 & 0.553 & 0.787 & 0.342 \\
\hline \multirow[t]{3}{*}{ MRI-CGCM2.3.2 } & 0.820 & 0.821 & 0.711 & 0.839 & 0.641 & 0.698 & 0.826 & 0.346 \\
\hline & \multicolumn{4}{|c|}{ Spatial RMSE (median) } & \multicolumn{4}{|c|}{ Spatial RMSE (MAD) } \\
\hline & $\begin{array}{l}\text { Onset } \\
\text { (pentads) }\end{array}$ & $\begin{array}{l}\text { Demise } \\
\text { (pentads) }\end{array}$ & $\begin{array}{l}\text { Duration } \\
\text { (pentads) }\end{array}$ & $\begin{array}{l}\text { Total precipitation } \\
(\mathrm{mm})\end{array}$ & $\begin{array}{l}\text { Onset } \\
\text { (pentads) }\end{array}$ & $\begin{array}{l}\text { Demise } \\
\text { (pentads) }\end{array}$ & $\begin{array}{l}\text { Duration } \\
\text { (pentads) }\end{array}$ & $\begin{array}{l}\text { Total precipitation } \\
(\mathrm{mm})\end{array}$ \\
\hline CGCM3.1(T63) & 10.3 & 9.9 & 3.4 & 298.5 & 2.7 & 4.9 & 2.7 & 300.5 \\
\hline CNRM-CM3 & 8.0 & 10.3 & 4.6 & 489.7 & 3.0 & 5.4 & 3.2 & 592.8 \\
\hline CSIRO-Mk3.0 & 24.0 & 12.1 & 3.7 & 276.4 & 3.6 & 5.1 & 2.8 & 312.8 \\
\hline ECHAM5 & 26.9 & 10.9 & 3.1 & 517.1 & 3.8 & 5.8 & 3.9 & 418.2 \\
\hline FGOALS-g1.0 & 10.4 & 9.8 & 4.4 & 287.4 & 2.7 & 6.2 & 2.6 & 380.4 \\
\hline GFDL-CM2.0 & 22.2 & 16.0 & 5.0 & 419.9 & 3.5 & 6.7 & 2.6 & 408.6 \\
\hline GFDL-CM2.1 & 14.2 & 13.2 & 4.9 & 443.5 & 3.9 & 7.3 & 3.2 & 441.9 \\
\hline MIROC3.2-hires & 16.1 & 9.2 & 3.8 & 192.6 & 3.0 & 4.9 & 2.3 & 308.0 \\
\hline MIROC3.2-medres & 6.9 & 7.4 & 4.3 & 255.3 & 2.9 & 4.5 & 2.0 & 315.4 \\
\hline MRI-CGCM2.3.2 & 9.7 & 9.5 & 3.5 & 254.8 & 2.4 & 3.7 & 1.8 & 280.5 \\
\hline
\end{tabular}


discrepancies are observed among models with respect to the skill in reproducing the spatial pattern of MAD. This is particularly remarkable for MAD of total precipitation. The best performance in this case is observed for MIROC3.2hires (SC 0.591). Among all IPCC models investigated here, MIROC3.2-hires, MIROC3.2-medres and MRICGCM2.3.2 are the most skilful in reproducing the overall spatial variation of median and MAD characteristics of SAMS.

The RMSE observed between median and MAD simulations and observations is, in all cases, very high for all models (Table 2). This is not surprising given that the RMSE averages the square of the difference of the magnitudes between observations and simulations grid point to grid point. Therefore, the analysis of RMSE should be considered along with $\mathrm{SC}$ as an indication of the skill of a model in reproducing SAMS spatial characteristics. Thus, taking these two parameters into account, MIROC3.2hires, MIROC3.2-medres and MRI-CGCM2.3.2 are the models that best characterize the spatial patterns of the median and MAD of onset, demise, duration and total precipitation. They show relatively high SC and low RMSE for most medians and MAD. Using the same rationale, the worst performance is observed for ECHAM5, GFDLCM2.0 and GFDL-CM2.1.

\section{Projections for the A1B scenario}

The same methodology applied for the 20CM simulations was used for the IPCC models in the A1B scenario. Median SAMS onset, demise, duration and total precipitation simulated for the A1B scenario were compared with the respective simulation for the $20 \mathrm{CM}$ run. The comparison was carried out by examining differences between medians obtained for the 20CM and A1B scenario.

Differences in median onsets are between 0 and 1 pentad over central Brazil, the core of SAMS (Fig. 10). In addition, there is no spatial coherence in the regions that passed the test of difference of medians at 5\% significance level in this region. Over northern Amazon, however, MIROC3.2hires (Fig. 10h), MIROC3.2-medres (Fig. 10i) and MRICGCM2.3.2 (Fig. 10j) indicate earlier onsets for the A1B scenario. Other models such as CGCMT63 (Fig. 10a), ECHAM5 (Fig. 10d) and FGOALS-g1.0 (Fig. 10e) indicate a delay in the rainy season of 1-2 pentads over the same region, but with no statistical significance at $5 \%$ level.

Differences in the date of the median demise are near zero over central Brazil for all models (Fig. 11). MRICGCM2.3.2 is the only model that simulates early onsets in the A1B scenario with statistical significance at 5\% level over a large fraction of the La Plata Basin in SA (Fig. 11j).
All models indicate shorter duration of the rainy season over the monsoon region (Fig. 12). However, these differences are not statistically significant in any region and for any model (Fig. 12). Likewise, there is no statistically significant difference in MAD and inter-quartile range over most of tropical SA (not shown). What these results indicate is that the characteristics of the distributions of onset, demise and duration of SAMS for the 20CM and A1B scenario are very similar.

On the other hand, distinct conclusions can be drawn with respect to total monsoonal precipitation. Figure 13 shows the difference between the median total precipitation for the A1B and 20CM scenarios for all IPCC models. Regions with statistically significant differences of medians are observed for all models. Nevertheless, there are remarkable discrepancies among IPCC models. For instance, CNRM-CM3 (Fig. 13a) shows statistically significant differences of about $250 \mathrm{~mm}$ over central Brazil, whereas MIROC3.2-medres (Fig. 13i) shows differences of the same magnitude but with opposite sign in the same region for $\mathrm{A} 1 \mathrm{~B}$ with respect to $20 \mathrm{CM}$ simulations. Nonetheless, six out of ten models examined here show a decrease of total monsoonal precipitation over central-east Brazil for the A1B scenario, with differences ranging from -300 to $-50 \mathrm{~mm}$ depending on the model. These models are CSIRO-Mk3.0 (Fig. 13c), FGOALS-g1.0 (Fig. 13e), GFDL-CM2.0 (Fig. 13f), GFDL-CM2.1 (Fig. 13g), MIROC3.2-hires (Fig. 13i) and MIROC2.2-medres (Fig. 13j). Furthermore, in four models (FGOALS-g1.0, GFDLCM2.0, MIROc3.2-medres and MIROC3.2-hires) differences are statistically significant at $5 \%$ level. These results are important because they indicate consistency in the simulations of IPCC models for the A1B scenario with respect to $20 \mathrm{CM}$ simulations. More importantly, they identify a reduction of the monsoonal precipitation in a future scenario of global change. Since FGOALS-g1.0, MIROC3.2-medres and particularly MIROC3.2-hires are models with high skill in representing the total monsoonal precipitation over central and eastern Brazil, a decrease in the total precipitation for the A1B in this region is likely a robust feature.

As discussed in the introduction and according to Meehl et al. (2005) a warmer planet could result in the enhancement of the potential for intense precipitation events and more snowstorms. Consistently with the present study, these authors also observed a decrease in the mean daily precipitation for central-eastern Brazil. A possible explanation for this apparent paradox may be found in Tebaldi et al. (2007). They verified that the IPCC models show a consistent signal of longer consecutive dry days and an increase in the rainfall intensity for the same region in a scenario of global change. Our results indicate that for most models and for centraleastern Brazil no statistically significant differences in the 
Fig. 10 Differences between the median of onset of the rainy season simulated for the A1B scenario and simulated for the 20CM scenario for each model: a CNRM-CM3; b CGCMT63; c CSIRO-MK3.0; d ECHAM5; e FGOALS-g1.0; f GFDLCM2.0; g GFDL-CM2.1; h MIROC3.2-hires; i MIROC3.2-medres and j MRICGCM2.3.2. Contour interval equal one pentad. Solid lines indicate positive values and dashed lines indicate negative values. Shading shows regions where the difference is statistically significant at $5 \%$ level

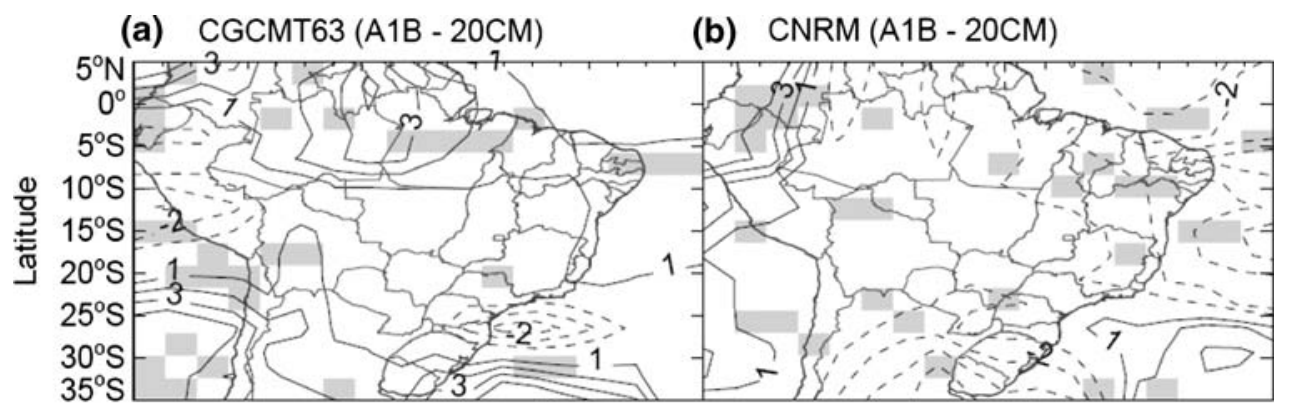

(c) $\operatorname{CSIRO~(A1B~-~20CM)~}$

(d) ECHAM5 (A1B - 20CM)

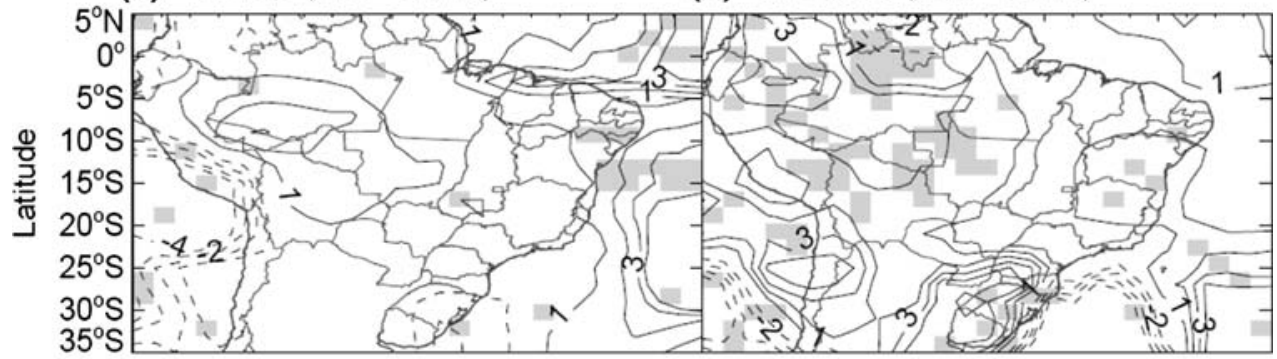

(e) FGOALS (A1B - 20CM)

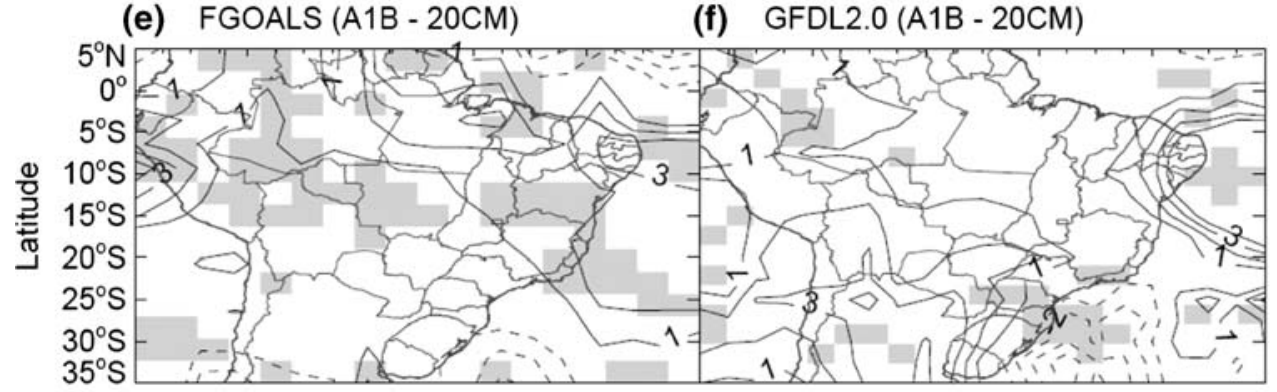

(g) GFDL2.1 (A1B - 20CM)

(h) MIROC-H (A1B - 20CM)

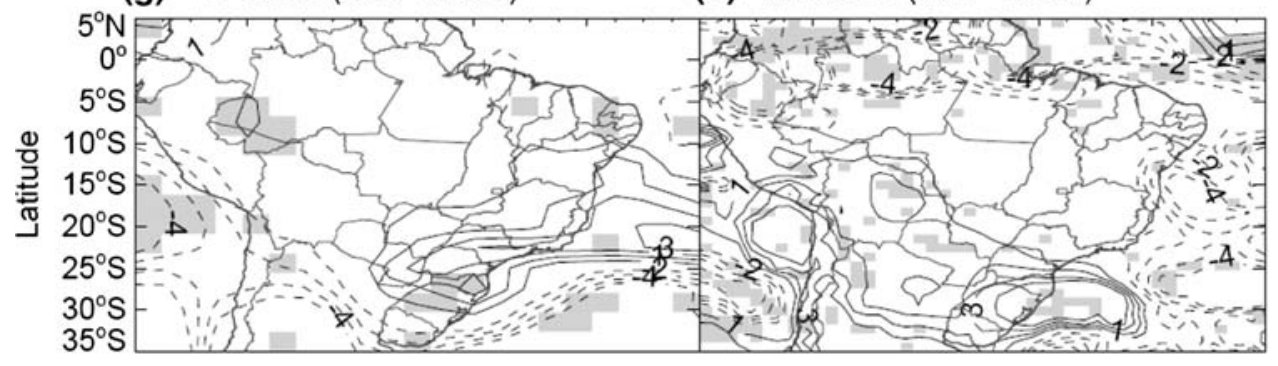

(i) MIROC-M (A1B - 20CM)

(j) $\operatorname{MRI}(A 1 B-20 \mathrm{CM})$

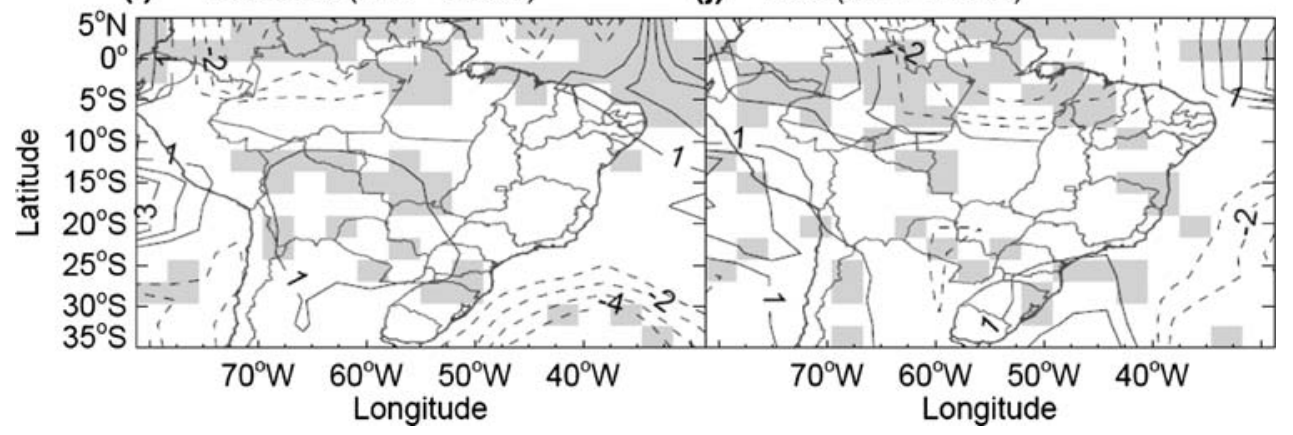

median onset, demise and duration are observed for the A1B scenario with respect to the present climate. These combined projections suggest that although rainfall intensity might increase in a future scenario of global change, the total monsoonal precipitation could decrease due to the increase in the number of dry days. 
Fig. 11 Same as in Fig. 10, but for median of demise of the rainy season. Contour interval equal one pentad. Solid lines indicate positive values and dashed lines indicate negative values. Shading shows regions where the difference is statistically significant at $5 \%$ level (a) $\operatorname{CGCMT63~(A1B~-~20CM)~}$

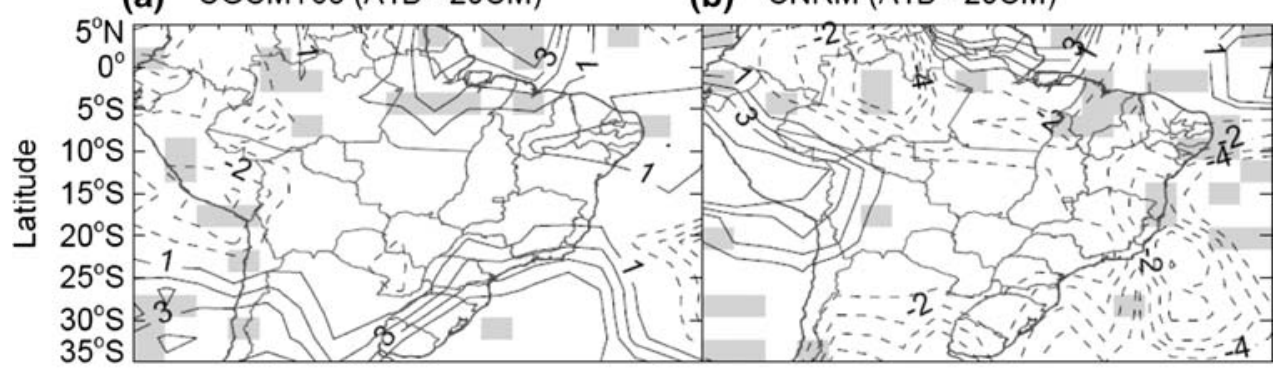

(c) $\operatorname{CSIRO}(\mathrm{A} 1 \mathrm{~B}-20 \mathrm{CM})$

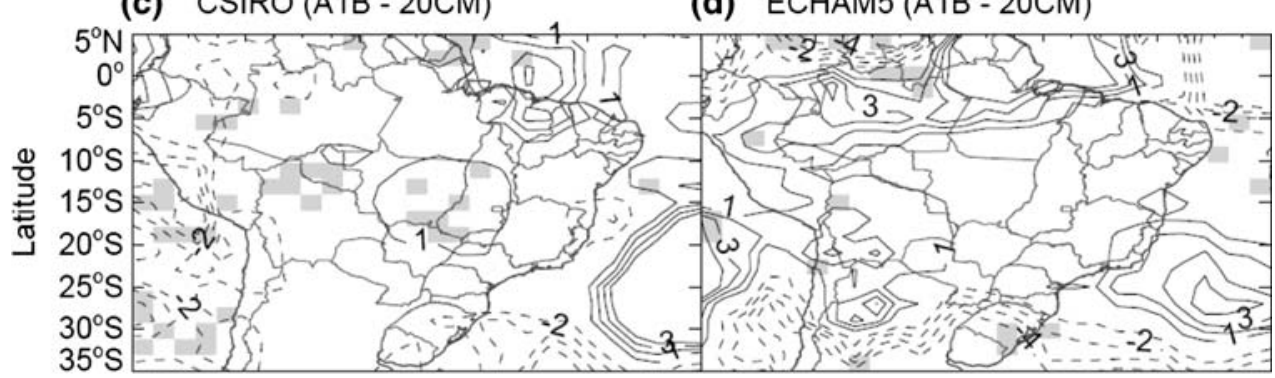

(e) FGOALS (A1B - 20CM)

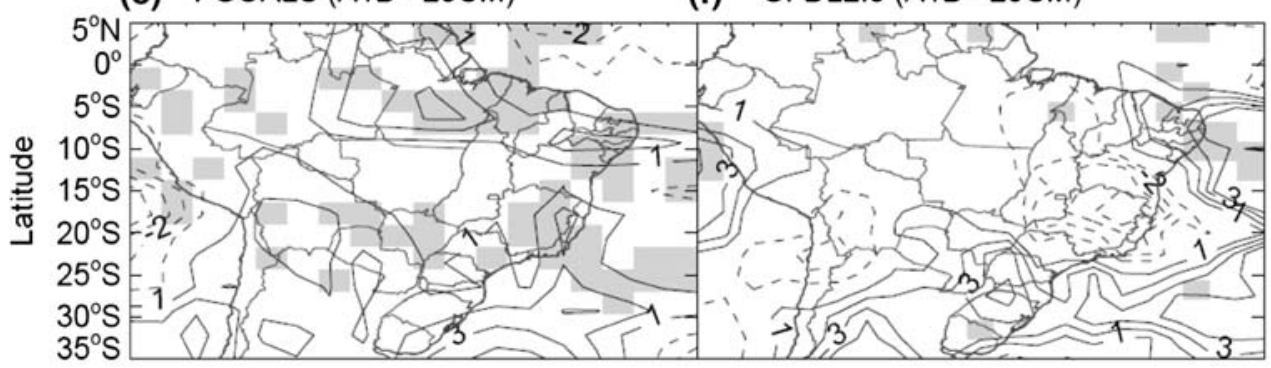

(g) GFDL2.1 (A1B - 20CM)

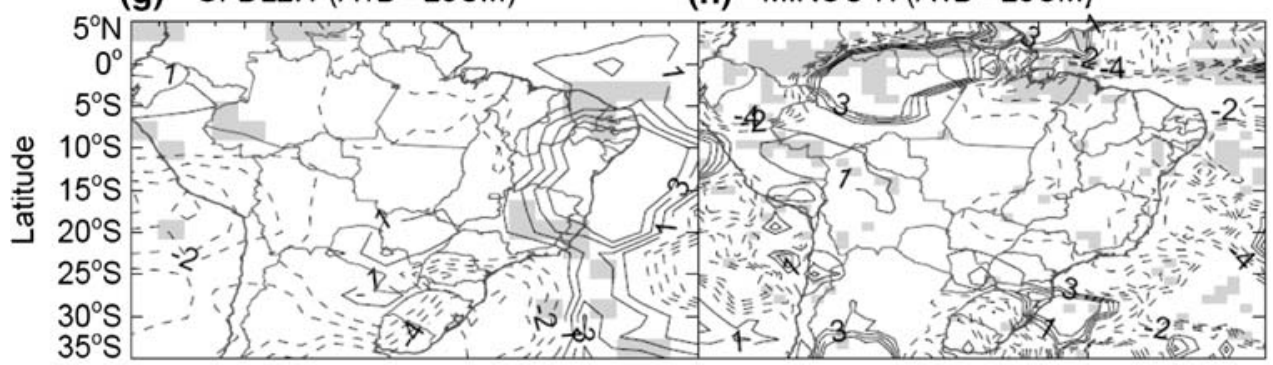

(i) MIROC-M (A1B - 20CM)

(j) $M R I(A 1 B-20 C M)$

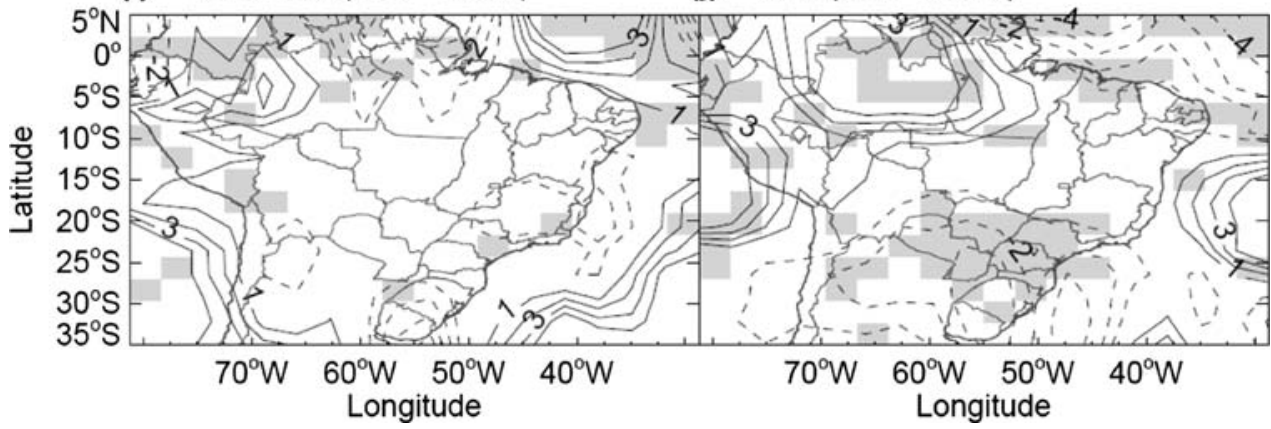

Another remarkable feature indicated by MIROC3.2hires is the increase in the monsoonal precipitation over North Brazil with maximum of more than $400 \mathrm{~mm}$ at the coast of Maranhão and Pará states in Brazil. These features are observed in a region where MIROC3.2-hires shows a maximum in total precipitation for the $20 \mathrm{CM}$ run that is 
Fig. 12 Same as in Fig. 10, but for median of duration of the rainy season. Contour interval equal one pentad. Solid lines indicate positive values and dashed lines indicate negative values. Shading shows regions where the difference is statistically significant at $5 \%$ level (a) $\operatorname{CGCMT63~(A1B~-~20CM)~}$

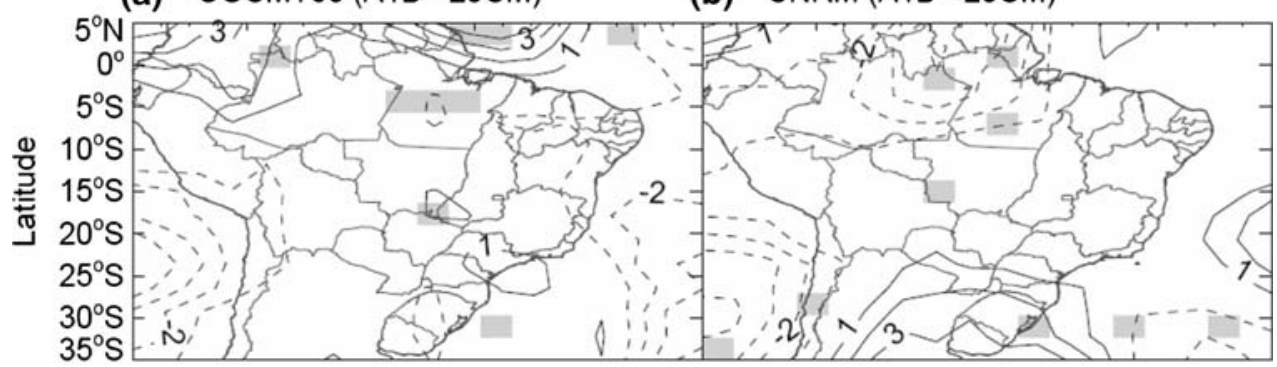

(c) $\operatorname{CSIRO~(A1B~-~20CM)~}$

(d) ECHAM5 (A1B - 20CM)

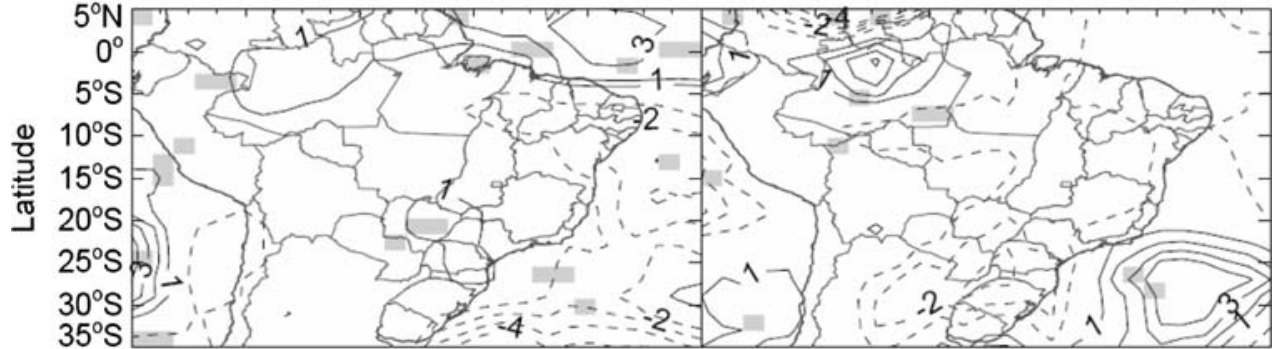

(e) FGOALS (A1B - 20CM)

(f) $\operatorname{GFDL2.0~(A1B~-~20CM)~}$

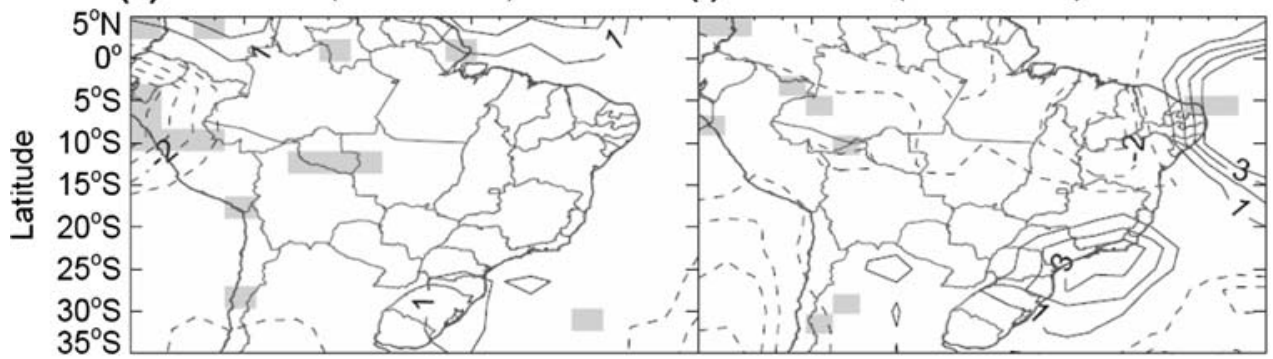

(g) GFDL2.1 (A1B - 20CM)

(h) MIROC-H (A1B - 20CM)
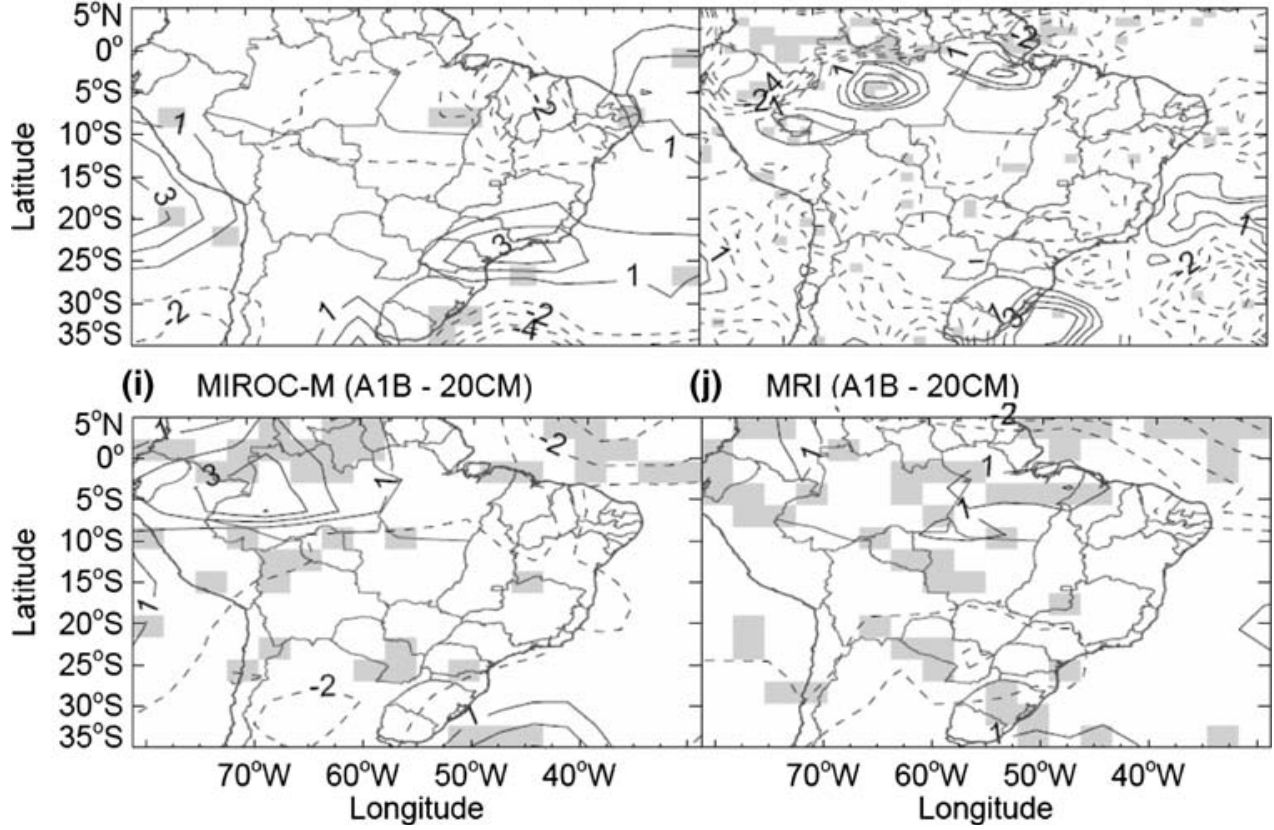

misplaced eastward of the actual observations (Fig. 4j). The increase in total precipitation over southern Brazil, Uruguay and Argentina in most models that show a decrease of total precipitation over eastern Brazil is consistent with observations of a seesaw in precipitation on several timescales reported in many previous studies (e.g. Vera et al. 2006a). 
Fig. 13 Same as in Fig. 10, but for median of total precipitation during the rainy season. Contour interval is equal $50 \mathrm{~mm}$. Solid lines indicate positive values and dashed lines indicate negative values. Shading shows regions where the difference is statistically significant at $5 \%$ level
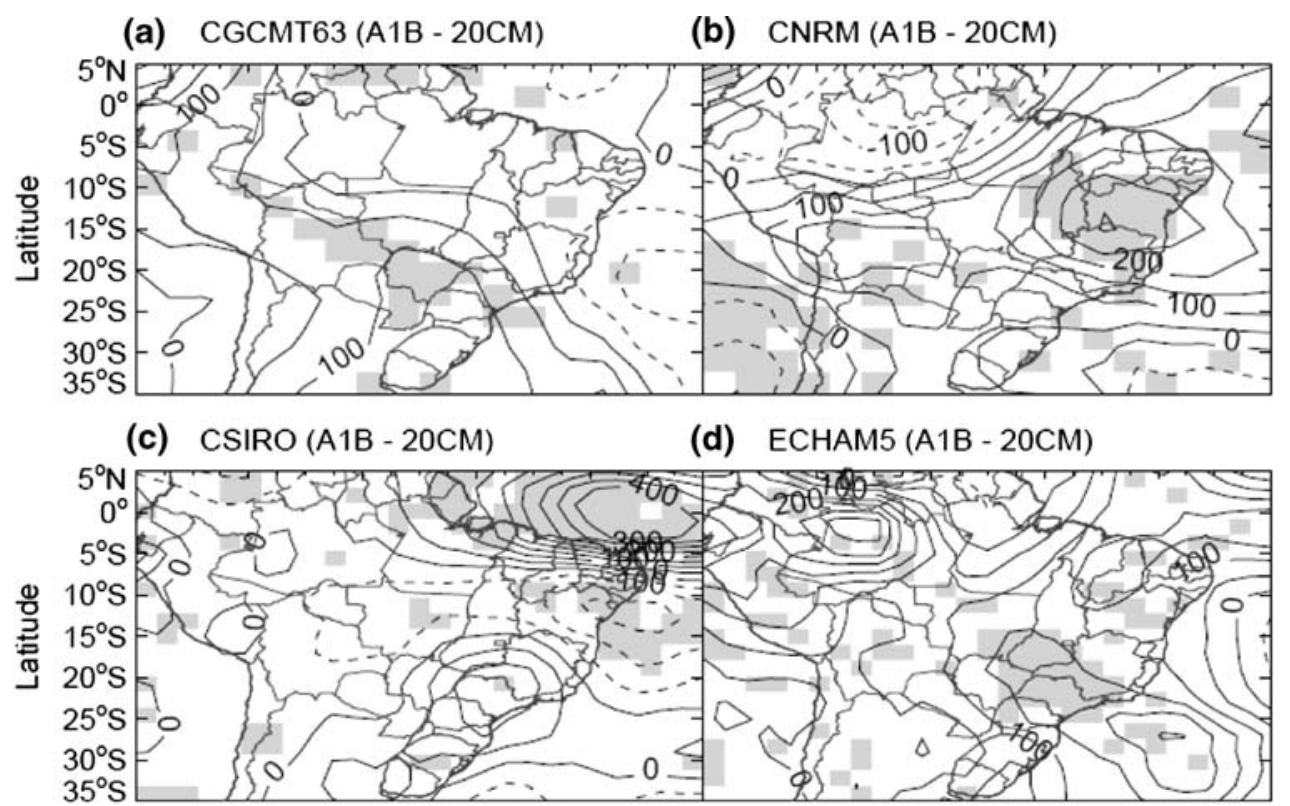

(e) FGOALS (A1B - 20CM)

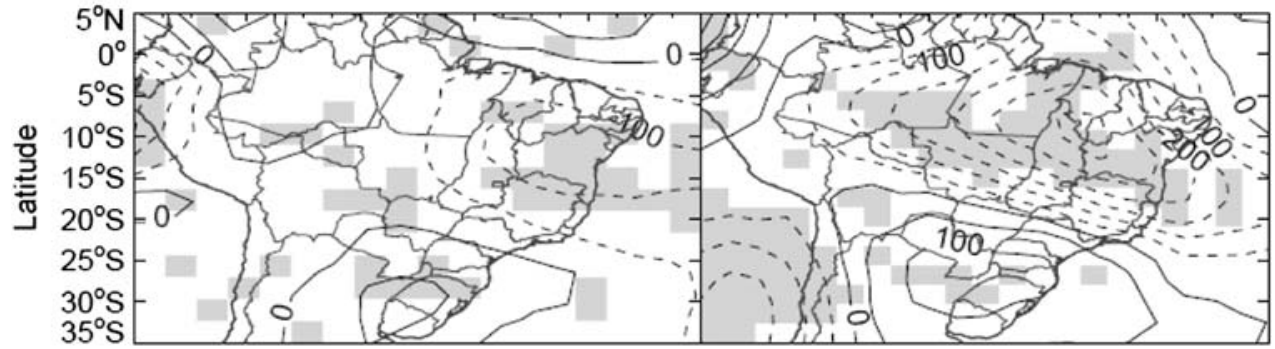

(g) GFDL2.1 (A1B - 20CM)

(h) MIROC-H (A1B - 20CM)

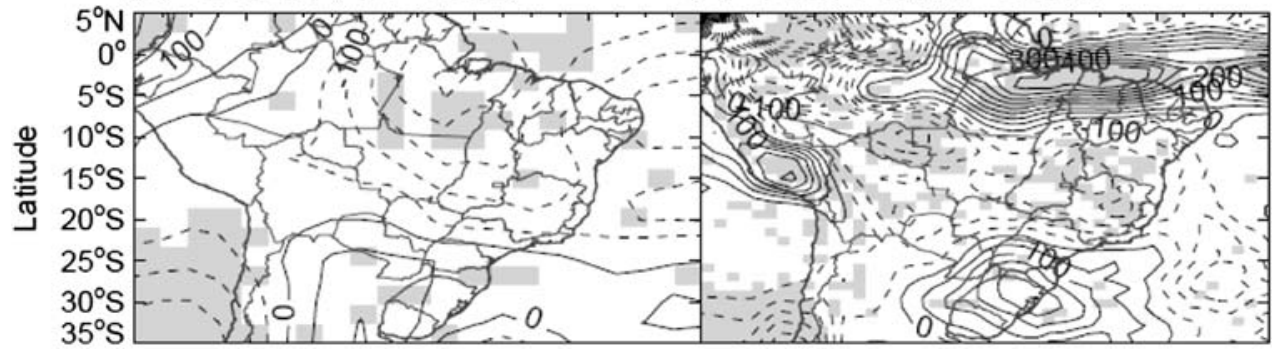

(i) MIROC-M (A1B - 20CM)

(j) $M R I(A 1 B-20 \mathrm{CM})$

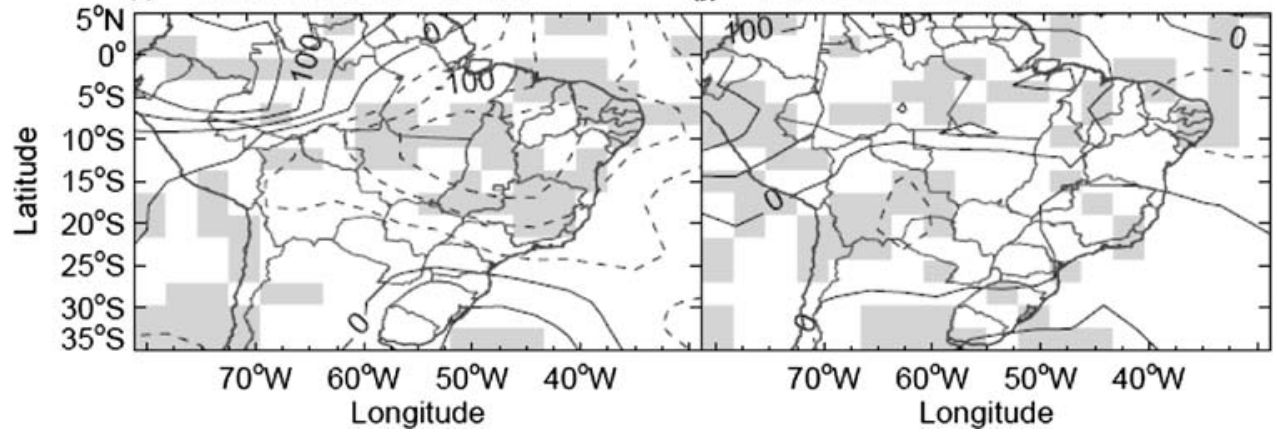

The difference between MAD for the A1B and 20CM scenarios was computed for the total monsoon precipitation. There is no statistically significant difference (at $5 \%$ level) observed for MAD, suggesting that the dispersion around the median is similar in both scenarios (not shown). This result does not exclude differences at the very end of 
the tails of the distributions that characterize extreme events, an issue not investigated in the present study.

\section{Conclusions}

This study examined simulations of SAMS characteristics by ten coupled IPCC global climate models with distinct physics and resolutions. The skill in the simulations was evaluated with GPCP precipitation during 28 rainy seasons (1979-2006). The focus of this analysis was on the correct simulations of the spatial patterns and variability of daily and total monsoonal precipitation, onset and demise dates, and duration of the monsoon. In this analysis every model was examined individually, in order to identify those that have poor skill against those with good skill in representing SAMS characteristics and how they can potentially influence the ensemble in the present climate and future scenarios of global change.

The SACZ is one of the most important features of SAMS. With the exception of ECHAM5, all models tend to represent an elongated band of precipitation emanating from the Amazon with an orientation NW-SE similar to the SACZ. MIROC3.2hires is the model that simulates more realistically precipitation daily average and standard deviation during the peak of the summer (DJF) in association with the SACZ. FGOALS-g1.0 and ECHAM5, on the other hand, show the poorest representation of the SACZ daily precipitation characteristics.

The mean annual cycle of precipitation was examined in some regions with distinct regimes. We show that over north SA, the annual cycle is poorly represented by most models. With the exception of MIROC3.2-hires, most models tend to underestimate precipitation during the peak of the rainy season. The misrepresentation of the ITCZ and its seasonal cycle seems to be one of the main reasons for the unrealistic out-of-phase annual cycles simulated near the equator by many GCMs. As a consequence, simulations of the total seasonal precipitation, onset and end of the rainy season diverge among models and are notoriously unrealistic over north and northwest Amazon for most models.

On the other hand, the good perspective in using IPCC models to understand and predict future climate changes in SAMS is that the large majority of the IPCC models realistically simulate the median characteristics and dispersion, and phase of the precipitation annual cycle over central SA for the 20CM runs. Previous studies have shown that this region is the core of the monsoon, where precipitation, low and high level winds, and humidity show the largest seasonal amplitude. In this region, the median precipitation during the rainy season is between 1,000 and $1,400 \mathrm{~mm}$. The median onset is observed between the beginning and the end of October and the demise occurs between end of March and
mid-April, with duration of the rainy season between 32 and 36 pentads. The best performance in simulating onset, end, duration and total monsoonal precipitation and its interannual variability is observed with the following models: MIROC3.2-hires, MIROC3.2-medres and MRICGCM2.3.2. The worst performance in simulating the same characteristics for central SA is observed with ECHAM5, GFDL-CM2.0 and GFDL-CM2.1. CSIRO-Mk3.0 model shows the best simulation of the evolution of the onset and end of the rainy season over the Amazon.

For the A1B scenario, the most coherent feature shown in six out of ten models is the decrease of total monsoonal precipitation over central and eastern SA, which coincides with a region where models show high skill in simulating SAMS characteristics in the 20CM runs. MIROC3.2-hires, which shows the best performance in simulating the characteristics of the total monsoonal precipitation and daily precipitation in the peak of the rainy season, indicates a deficit in precipitation between -100 and $-200 \mathrm{~mm}$ in the A1B scenario comparatively to the 20CM, extending approximately from southern Amazon toward eastern Brazil. Today, this region covers an area of intensive landuse change, mostly due to expansion of agriculture and pasture activities. Moreover, the northwestern boundary of this region makes a frontier with the Amazon forest, a region where large rate of deforestation, soil degradation and human conflicts have been observed in the last decade (IPCC 2007). Regional analyses are therefore necessary to understand further impact of the projected decrease in precipitation in this region.

Acknowledgments We thank Dr. Charles Jones and Dr. Humberto R. Rocha and the two anonymous reviewers for their valuable comments and suggestions for this manuscript. We also thank the Program for Climate Model Diagnosis and Intercomparison (PCMDI) and the WCRP's Working Group on Coupled Modeling (WGCM) for making available the WCRP CMIP3 multi-model dataset. GPCP data were provided by NOAA. The authors greatly acknowledge the financial support of the following agencies: FAPESP (Proc: 02/09289-9); R. J. Bombardi FAPESP (06/53769-6); L. M. V. Carvalho CNPq (Proc: 482447/2007-9 and 474033/2004-0) and NOAA Office of Global Programs (NOAA NA07OAR4310211).

\section{References}

Ashrit RG, Douville H, Kumar KR (2003) Response of the Indian monsoon and ENSO-monsoon teleconnection to enhanced greenhouse effect in the CNRM coupled model. J Meteorol Soc Jpn 81:779-803

Carril AF, Menéndez CG, Nuñez MN (1997) Climate change scenarios over the South American region: an intercomparison of coupled general atmosphere-ocean circulation models. Int $\mathbf{J}$ Climatol 17:1613-1633

Cariolle D, Déqué M (1986) Southern hemisphere medium-scale waves and total ozone disturbances in a spectral general circulation model. J Geophys Res 91:10825-10846 
Cariolle D, Lasserre-Bigory A, Royer J-F et al (1990) A general circulation model simulation of the springtime Antarctic ozone decrease and its impact on mid-latitudes. J Geophys Res 95:1883-1898

Carvalho LMV, Jones C, Liebmann B (2002a) Extreme precipitation events in southeastern South America and large-scale convective patterns in the South Atlantic convergence zone. J Clim 15:2377-2394

Carvalho LMV, Jones C, Silva Dias MAF (2002b) Intraseasonal large-scale circulations and mesoscale convective activity in tropical South America during the TRMM-LBA campaign. J Geophys Res. doi:10.102/2001JD000745

Carvalho LMV, Jones C, Liebmann B (2004) The South Atlantic convergence zone: persistence, intensity, form, extreme precipitation and relationships with intraseasonal activity. J Clim 17:88-108

Coelho CAS, Uvo CB, Ambrizzi T (2002) Exploring the impacts of the tropical Pacific SST on the precipitation patterns over South America during ENSO periods. Theor Appl Climatol 71:185197

Dai A (2006) Precipitation characteristics in eighteen coupled climate models. J Clim 19:4605-4630

Delworth TL, Broccoli AJ, Rosati A et al (2006) GFDLs CM2 global coupled climate models-Part 1: formulation and simulation characteristics. J Clim 19:643-674

Flato GM, Boer GJ, Lee WG et al (2000) The Canadian centre for climate modelling and analysis global coupled model and its climate. Clim Dyn 16:451-467

Gan MA, Kousky VE, Ropelewski CF (2004) The South America monsoon circulation and its relationship to rainfall over westcentral Brazil. J Clim 17:47-66

Giorgi F, Francisco R (2000) Evaluating uncertainties in the prediction of regional climate change. Geophys Res Lett 27:1295-1298

Gordon HB, Rotstayn LD, Mcgregor JL et al (2002) The CSIRO Mk3 climate system model. CSIRO Atmospheric Research Tech. Available via DIALOG. http://www.dar.csiro.au/publications/ gordon_2002a.pdf. Accessed 20 Sep 2006

Grimm AM, Barros VR, Doyle ME (1998) Precipitation anomalies in southern South America associated with El Niño and La Niña events. J Clim 11:2863-2880

Grimm AM, Barros VR, Doyle ME (2000) Climate variability in southern South America associated with El Niño and La Niña events. J Clim 13:35-58

Hasumi H, Emori S (2004) K-1 coupled GCM (MIROC). Available via DIALOG. http://www.ccsr.u-tokyo.ac.jp/kyosei/hasumi/ MIROC/tech-repo.pdf. Accessed 20 Sep 2006

IPCC (2001): Climate Change (2001) Impacts, adaptation, and vulnerability. In: McCarthy JJ, Canziani OF, Leary NA, Dokken DJ, White KS (eds) Contribution of working group II to the third assessment report of the intergovernmental panel on climate change. Cambridge University Press, Cambridge

IPCC (2007): Climate Change (2007) The physical science basis. In: Solomon S, Qin D, Manning M, Chen Z, Marquis M, Averyt KB, Tignor M, Miller HL (eds) Contribution of working group I to the fourth assessment. Report of the intergovernmental panel on climate change. Cambridge University Press, Cambridge

Jones C, Carvalho LMV (2002) Active and break phases in the South American monsoon system. J Clim 15:905-914

Kayano MT, Kousky VE (1992) On the monitoring of intraseasonal oscillations. Rev Bras Meteorol 7:593-602 (in Portuguese)

Kharin VV, Zwiers FW, Zhang X et al (2007) Changes in temperature and precipitation extremes in the IPCC ensemble of global coupled model simulations. J Clim 20:1419-1444

Kodama Y-M (1992) Large-scale common features of subtropical precipitation zones (the Baiu Frontal Zone, the SPCZ, and the
SACZ). Part I: characteristics of subtropical frontal zones. J Meteorol Soc Jpn 70:813-835

Kousky VE (1988) Pentad outgoing longwave radiation climatology for the South American sector. Rev Bras Meteorol 3:217-231

Labraga LC, Lopez M (1997) A comparison of the climate response to increased carbon dioxide simulated by general circulation models with mixed-layer and dynamic ocean representations in the region of South America. Int J Climatol 17:1635-1650

Lambert SJ, Boer GJ (2001) CMIP1 evaluation and intercomparison of coupled climate models. Clim Dyn 17:83-106

Lenters JD, Cook KH (1999) Summertime precipitation variability over South America: role of the large-scale circulation. Mon Wea Rev 127:409-431

Liebmann B, Marengo JA (2001) Interannual variability of the rainy season and rainfall in the Brazilian Amazon Basin. J Clim 14:4308-4318

Liebmann B, Jones C, Carvalho LMV (2001) Interannual variability of extreme precipitation events in the State of São Paulo, Brazil. J Clim 14:208-218

Liebmann B, Allured D (2005) Daily precipitation grids for South America. Bull Am Meteorol Soc 86:1567-1570

Liebmann B, Camargo SJ, Seth A, Marengo JA et al (2007) Onset and end of the rainy season in South America in observations and the ECHAM 4.5 atmospheric general circulation model. J Clim 20:2037-2050

Lincoln MA, Marengo JA, Camargo H et al (2005) The onset of the rainy season over southeast Brazil, Part-1. Observational studies. Rev Bras Metor 20:385-394 (in Portuguese)

Magaña V, Ambrizzi T (2005) Dynamics of subtropical vertical motions over the Americas during El Niño Boreal winters. Atmósfera 18:211-235

Marengo JA (2003) Ensemble simulation of regional rainfall features in the CPTEC/COLA atmospheric GCM. Skill and predictability assessment and applications to climate predictions. Clim Dyn 21:459-475

Marengo JA, Liebmann B, Kousky VE et al (2001) Onset and end of the rainy season in the Brazilian Amazon basin. J Clim 14:833852

Meehl GA, Arblaster JM, Tebaldi C (2005) Understanding future patterns of increased precipitation intensity in climate model simulations. Geophys Res Lett. doi:10.1029/2005GL023680

Muza MN, Carvalho LMV (2006) Intraseasonal and interannual variability of extreme precipitation and drought over southern Amazon during the Austral summer. Rev Bras Meteorol 21:2941 (in Portuguese)

Roeckner E, Bäuml G, Bonaventura L et al (2003) The atmospheric general circulation model ECHAM5. Part 1. Available via DIALOG. http://www.mpimet.mpg.de/fileadmin/publikationen/ Reports/max_scirep_349.pdf. Accessed 8 Jan 2008

Salas-Mélia D, Chauvin F, Déqué M et al (2005) Description and validation of the CNRM-CM3 global coupled model. Available via DIALOG. http://www.cnrm.meteo.fr/scenario2004/paper_ cm3.pdf. Accessed 8 Jan 2008

Seth A, Rauscher SA, Camargo SJ (2007) RegCM3 regional climatologies for South America using reanalysis and ECHAM global model driving fields. Clim Dyn 28:461-480

Silva AE, Carvalho LMV (2007) Large-scale index for South America monsoon (LISAM). Atmos Sci Lett. doi:10.1002/asl.150

Silva MES, Carvalho LMV, Dias MAFS et al (2006) Complexity and predictability of daily precipitation in a semi-arid region: an application to Ceará, Brazil. Nonlinear Process Geophys 13:651659

Sun Y, Solomon S, Dai A (2005) How often does it rain? J Clim 19:916-934

Tebaldi C, Hayhoe K, Arblaster J et al (2007) Going to the extremes: an intercomparison of model-simulated historical and future 
changes in extreme events. Clim Change 79:185-211. doi: 10.1007/s10584-006-9051-4

Vera C, Higgins W, Ambrizzi T et al (2006a) Toward a unified view of the American monsoon systems. J Clim 19:4977-5000

Vera C, Silvestri G, Liebmann B (2006b) Climate change scenarios for seasonal precipitation in South America from IPCC-AR4 models. Geophys Res Lett. doi:10.1029/2006GL025759

Wilks DS (2006) Statistical methods in the atmospheric sciences. Academic Press, New York

Xie P, Janowiak JE, Arkin PA et al (2003) GPCP pentad precipitation analyses: an experimental dataset based on gauge observations and satellite estimates. J Clim 16:2197-2214
Yu Y, Zhang X, Guo Y (2004) Global coupled ocean atmosphere general circulation models in LASG/IAP. Adv Atmos Sci 21:444-455

Yukimoto S, Noda A, Kitoh A et al (2006) Present-day climate and climate sensitivity in the Meteorological Research Institute Coupled GCM, version 2.3 (MRI-CGCM2.3). J Meteorol Soc Jpn 84:333-363

Zhou J, Lau KM (1998) Does a monsoon climate exist over South America? J Clim 11:1020-1040 